\title{
ERS guidelines on the assessment of cough
}

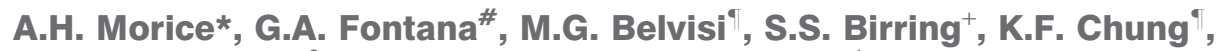 \\ P.V. Dicpinigaitis ${ }^{\S}$, J.A. Kastelik*, L.P. McGarvey ${ }^{\ddagger}$, J.A. Smith**, \\ M. Tatar ${ }^{\# \#}$ and J. Widdicombe
}

\section{CONTENTS}

\section{Background \\ Cough monitors \\ Animal models of cough \\ SUMMARY OF KEY POINTS AND RECOMMENDATIONS \\ Cough}

Summary of key points and recommendations

Capsaicin and citric acid inhalation cough challenge

Cough induced by inhalation of aqueous solutions

Assessment of quality of life of patients with chronic cough

Design and conduct of clinical trials of antitussive drugs

1) All basic scientific articles should refer to cough as a three-phase motor act. For the purposes of acoustic recordings in clinical studies, however, cough should be described as a forced expulsive manoeuvre or manoeuvres against a closed glottis that are associated with a characteristic sound or sounds.

2) All scientific articles should include a clear definition of what the authors have used as their definition of cough.

\section{Capsaicin and citric acid inhalation cough challenge}

1) The methodology for the performance of inhalation cough challenge should be standardised so as to facilitate universal interpretation and comparison of data generated by different laboratories.

2) Comprehensive normal ranges need to be developed using the standardised methodology advocated in the present document.

3) The single-breath concentration-response method using a flow-limited dosimeter is recommended for most experimental protocols.

4) Both $C_{2}$ and $C_{5}$ should be recorded.

5) Since there is wide inter-individual variation, cough challenge data have no intrinsic significance, but may usefully be used to follow change in cough reflex sensitivity in an individual.

\section{Cough induced by inhalation of aqueous solutions}

1) Aerosolised aqueous solutions represent a useful experimental tool in cough research.

2) The cough challenge with ultrasonic distilled water (fog) is difficult to standardise since it is highly dependent upon nebuliser output.

3) Consideration should be given to potential adverse events, such as bronchoconstriction and cross-infection.

\section{Cough monitors}

1) No cough monitor is currently the gold standard.

2) Monitors should be developed that are ambulatory, are capable of being digitally processed and permit prolonged (24-h) recording.

3) There is little to commend any particular method of quantifying cough over any other.

\section{Assessment of quality of life of patients with chronic cough}

1) Cough can have profound effects on health status, which can be assessed by cough-specific health status questionnaires.

2) Cough visual analogue scale (VAS, $0-100 \mathrm{~mm}$ ) should be used to assess cough severity in patients with chronic cough.

3) Patients with chronic cough should be assessed with cough-specific quality-of-life questionnaires in clinical studies.
AFFILIATIONS

${ }^{*}$ Cardiovascular and Respiratory

Studies, Respiratory Medicine, Castle

Hill Hospital, Cottingham,

'National Heart \& Lung Institute,

Imperial College London,

+Kings College Hospital, and

"University of London, London, and

${ }^{f}$ Queen's University of Belfast,

Belfast, and

**Education and Research Centre,

University of Manchester,

Manchester, UK.

\#University of Florence, Florence, Italy.

${ }^{\S}$ Albert Einstein College of Medicine, and Montefiore Medical Center.

New York, NY, USA.

\#\# Jessenius Medical School,

Comenius University, Martin,

Slovakia.

\section{CORRESPONDENCE}

A.H. Morice, Cardiovascular and Respiratory Studies, Respiratory

Medicine, Castle Hill Hospital, Castle Road, Cottingham, East Yorkshire,

HU16 5JQ, UK

Fax: 441482624068

E-mail: a.h.morice@hull.ac.uk

Received:

August 022006

Accepted after revision:

December 142006

STATEMENT OF INTEREST

Statements of interest for A.H. Morice, S.S. Birring, K.F. Chung, J.A. Kastelik, J.A. Smith and M. Tatar can be found at

www.erj.ersjournals.com/misc/ statements.shtml

European Respiratory Journa Print ISSN 0903-1936

Online ISSN 1399-3003 


\section{Animal models of cough}

1) The most useful animal model of cough is the conscious guinea pig.

2) Both sound and airflow should be used to define a cough event.

\section{Design and conduct of clinical trials of antitussive drugs}

1) The experimental model in which antitussive drugs are tested depends greatly upon the mode of action of the agent.

2) Normal volunteer studies should be designed in the knowledge that a large placebo effect is likely.

3) In acute cough, parallel group studies are required.

4) In chronic cough, the patient population studied should be defined by a diagnostic test.

\section{BACKGROUND}

Cough is the most common symptom for which individuals seek medical advice [1,2]. An acute cough is often the most prominent symptom of the common cold, which itself is the most frequent illness to afflict mankind. In the USA, the direct and indirect costs of the common cold have been estimated at US $\$ 40$ billion per annum [3]. Chronic cough, as the sole presenting complaint, is known to account for $10-38 \%$ of all referrals made to respiratory physicians $[4,5]$. Recently, the European Respiratory Society (ERS) published guidelines on the management of cough [6]. The aim of that document, as of guidelines produced by the American College of Chest Physicians, was to provide consensus regarding the diagnosis and treatment of cough in both adults and children [7]. However, little attention has been given to the accurate clinical and scientific assessment of coughing. In 2004, the ERS approved the setting up of a task force with the intention of producing recommendations for cough assessment. The main objective was to produce a practical document, which would provide helpful guidance to researchers, clinicians, the pharmaceutical industry and regulatory authorities. It was agreed that the scope of this document should include recommendations on the following key elements: 1) safe standardised methods of inhalation cough challenge; 2) reliable, reproducible and relevant clinical cough recording and analysis; 3) clinical assessment of cough-related quality of life; 4) appropriate animal models in which to evaluate novel cough treatments; and 5) areas for future research. It is envisaged that an effective document would contribute to improved patient care, enhance the quality of cough research and ultimately assist in the development of effective new therapies.

\section{The need for recommendations regarding the assessment of cough}

In addition to the gaps in the existing literature, four major factors justify the need for such a publication.

1) Since the mid-1960s, there has been a sharp increase in the number of published manuscripts concerned with various aspects of cough in human and animal studies. In a PubMed search ranging 1966-2005 and limited to the keyword "cough", there were 22,744 citations, more than for other common respiratory symptoms including the term dyspnoea/dyspnea or wheeze. This represents not only an absolute increase but also a two-fold relative increase in cough publications. The incremental rise in citations in the four decades spanning this period is displayed in table 1 . The publications are geographically diverse, spanning five continents, and highlight the importance and frequency with which cough presents as a clinical problem.

2) The morbidity of cough is not trivial, and the assessment of cough patients is incomplete without appreciation of the associated clinical impact. A series of cough-specific quality-oflife questionnaires have been designed to capture this, but agreement regarding their interpretation and clinical application is needed $[8,9]$. New technologies designed to objectively record and analyse cough events are rapidly being developed. Recommendations regarding clinical and pharmacologically relevant end-points for such devices are required.

3) The value of inhalation cough challenge testing as a research tool in both human and animal studies is established [10, 11]. On review of the existing literature, different methods of challenge have been identified, with wide variation in the choice of tussive agents, delivery device and test end-point employed. Standardisation of cough challenge methodology is required if reliable comparisons of experimental results between laboratories are to be made. In order to ensure continued ethical review board support for cough research, a standardised approved method of safe inhalation challenge testing is required.

4) Although specific therapy directed at the underlying cause of cough is usually successful, there are no particularly effective nonspecific cough treatments. These are desperately needed for patients with idiopathic cough, for those troubled with cough due to pulmonary fibrosis and lung cancer, and when established treatments for asthma and chronic obstructive pulmonary disease (COPD) are ineffective. Drug development is currently hampered by the lack of consensus as to the appropriate animal model for testing of putative novel therapies. Recommendations for the reliable and informative testing of new therapies in animal models would be a major step towards effective cough therapy.

\section{Methods}

The task force was composed of a number of invited participants, identified for their particular expertise in the area of cough assessment and treatment. The initial meeting of task force members was held at the 2004 ERS Congress in Glasgow,

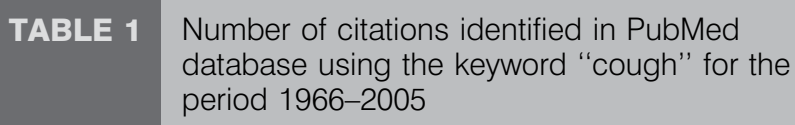
database using the keyword "cough" for the period 1966-2005

\begin{tabular}{lc} 
Period & Citations \\
\hline $\mathbf{1 9 6 6 - 1 9 7 5}$ & \\
$\mathbf{1 9 7 6 - 1 9 8 5}$ & 2262 \\
$\mathbf{1 9 8 6 - 1 9 9 5}$ & 2968 \\
$\mathbf{1 9 9 6 - 2 0 0 5}$ & 6564 \\
\hline
\end{tabular}


UK, and followed by subsequent meetings in 2005 in Amsterdam, the Netherlands, and later that year at the ERS Congress in Copenhagen, Denmark. At the first meeting, it was agreed that, where possible, recommendations should be based on the peer-reviewed literature (original publications and review articles). However, it was apparent that in many areas of interest, including cough reflex testing, use of qualityof-life questionnaires and new cough recording technologies, only limited data (such as meeting abstracts) existed. Consequently, the opportunity to produce evidence-based guidelines was limited. In such circumstances, recommendations were based on the consensus of experience of task force participants.

Individuals and small groups were allocated specific topics and, after conducting a literature review, asked to produce an article for consideration at the subsequent task force meeting. Based on the group discussion at these meetings, a series of recommendations were agreed upon.

\section{Structure of the document}

The present document is prefaced with an executive summary of key points and recommendations. The subsequent sections address the individual components of cough assessment, namely cough challenge in humans, cough event recording, assessment of cough quality of life, animal models of cough, and the design and conduct of clinical trials of antitussive drugs. Each section begins with a summary of the existing literature followed by a concluding statement highlighting areas for future research and finally the task force recommendations.

\section{Defining cough}

Although usually defined in textbooks, a clear definition of cough is lacking in the majority of scientific papers concerning cough [12]. For the purpose of the present recommendations, two possible definitions of cough, which have been used elsewhere, are provided [13, 14].

1) Cough is a three-phase expulsive motor act characterised by an inspiratory effort (inspiratory phase), followed by a forced expiratory effort against a closed glottis (compressive phase) and then by opening of the glottis and rapid expiratory airflow (expulsive phase) [13].

2) Cough is a forced expulsive manoeuvre, usually against a closed glottis and which is associated with a characteristic sound [14].

Although some similarities exist, the major discrepancy between these two definitions relates to the respiratory patterns associated with cough. In particular, the preceding inspiratory phase, which constitutes the first definition, is believed to be one of a number of distinguishing features between cough and another airway defensive reflex, the expiration reflex [12].

Furthermore, neither definition adequately deals with the common clinical scenario whereby an initial cough is followed by a series of cough efforts. For the patient, this is often described as a cough "bout" or "attack". To the researcher, they may represent individual coughs or an extended single cough. Clearly, this is of importance to those concerned with the accurate recording of cough frequency. For the physician and, most critically, the patient, a definition that reflects the sensation associated with an urge to cough, the intensity of the cough and its impact on health status overrides any such debate.

For the purpose of the assessment of cough, the present task force has adopted the following recommendations.

\section{Recommendations}

1) All basic scientific articles should refer to cough as a threephase motor act. For the purposes of acoustic recordings in clinical studies, however, cough should be described as a forced expulsive manoeuvre or manoeuvres against a closed glottis that are associated with a characteristic sound or sounds.

2) All scientific articles should include a clear definition of what the authors have used as their definition of cough.

\section{CAPSAICIN AND CITRIC ACID INHALATION COUGH CHALLENGE}

\section{Methodology}

The inhalation cough challenge permits measurement of the sensitivity of the cough reflex and assessment of the antitussive effects of specific therapies. In general, inhalation cough challenge testing can be divided into methods that use acid and non-acid tussives. Capsaicin, the most commonly used non-acid tussive to experimentally induce cough in humans, was first described in 1984 [15]. Citric and tartaric acid are the most widely used acid tussigens [16]. Citric acid inhalation cough challenge was described and formally characterised in the mid-1950s [16, 17]. Both citric acid and capsaicin can induce cough in a dose-dependent and reproducible manner $[16,18]$.

Unfortunately, because of the lack of standardisation of cough challenge methodology in terms of equipment, preparation of solutions, method of administration, nebuliser output, inspiratory flow rate and dose of aerosol per breath, comparisons of cough sensitivity data currently in the literature from different institutions are not valid. In the present section, recommendations that will assist in the standardisation of inhalation cough challenge testing using both acid and non-acid tussigens are proposed.

\section{Preparation and storage of capsaicin solutions}

Capsaicin $(30.5 \mathrm{mg}$ ) is dissolved in $1 \mathrm{~mL}$ pure ethanol and $1 \mathrm{~mL}$ polyoxyethylene sorbitan (Tween 80) and then further dissolved in $8 \mathrm{~mL}$ physiological saline solution to yield a $0.01 \mathrm{M}$ stock solution $[19,20]$. Without the detergent Tween 80 , a cloudy rather than clear solution results. The solution is subsequently diluted with saline in order to obtain serial doubling concentrations ranging $0.49-1,000 \mu \mathrm{M}$. If healthy volunteers are to be tested, the lowest concentration prepared is $0.98 \mu \mathrm{M}$, since, in the authors' experience, induction of cough at this concentration is rare.

It is unclear how often fresh stock solution should be prepared. A recent study concluded that capsaicin solutions of $\geqslant 4 \mu \mathrm{M}$ are stable for $1 \mathrm{yr}$ if stored at $4{ }^{\circ} \mathrm{C}$ and protected from light [21]. 


\section{Preparation of citric acid}

Serial dilution of $3 \mathrm{M}$ citric acid stock solution in sterile $0.9 \%$ saline solution is performed in order to obtain serial doubling concentrations ranging 1.95-3,000 mM [22-24]. In healthy volunteers, the lowest concentration prepared is $7.8 \mathrm{mM}$. For both capsaicin and citric acid, fresh dilutions from a stock solution are prepared on each day of testing. The stock solution is maintained at $\sim-10^{\circ} \mathrm{C}$ for capsaicin and $4{ }^{\circ} \mathrm{C}$ for citric acid. The authors recommend that fresh solutions are prepared for each challenge.

Capsaicin and citric acid are delivered in serial doubling concentrations (the lower concentration is unlikely to influence the higher one), with inhalation of $0.9 \%$ saline solution randomly interspersed to increase challenge blindness [22-24].

\section{Administration of capsaicin and citric acid}

The two main methods of capsaicin and citric acid delivery during cough challenge testing are the single-dose and doseresponse methods [25]. In the former method, a single concentration of capsaicin or citric acid is employed. The dose-response method can involve either the administration of single vital-capacity breaths of incremental concentrations of capsaicin or citric acid via a dosimeter-controlled nebuliser or the tidal-breath inhalation of incremental concentrations of tussive agent, each over a fixed time period, usually 15-60 s.

In most experimental circumstances, the single-breath doseresponse method is preferred because of the accuracy and reproducibility of the dose delivered and the ease with which a tussive response can be determined. With capsaicin and citric acid inhalation occurring over a prolonged time period, variations in respiratory frequency and tidal volume are likely to cause significant variations in the amount of aerosol delivered from subject to subject, as well as from one concentration to another in an individual subject. This would be of particular concern during the administration of concentrations that induce significant coughing, thereby preventing the subject from inhaling the tussive agent for a significant portion of the fixed time period of aerosol delivery. Nevertheless, a recently published comparison of the tidal breathing and dosimeter methods of capsaicin inhalation challenge demonstrated both to be reproducible, with good agreement between the two methods [26].

Optimisation of reproducibility of capsaicin and citric acid cough challenges

Inspiratory flow rate

The rate of inspiratory flow affects the pattern of deposition of aerosol within the airways. Variations in inspiratory flow rate have been demonstrated to affect the results of capsaicin [27] and citric acid [28] cough challenge. For example, lower inspiratory flow rates $\left(50\right.$ versus $150 \mathrm{~L} \cdot \mathrm{min}^{-1}$ ) result in greater cough response to citric acid [28]. Therefore, the flow rate needs to be constant regardless of effort, since, unless inspiratory flow rate is controlled, variable amounts of tussive agent will be delivered to different subjects, and even breathto-breath variations may occur in a given subject within the same study. Such potential variability in aerosol delivery may affect the results of studies in which reproducibility of cough challenge results are crucial, such as in pharmacological studies incorporating cough sensitivity measurement before and after drug therapy, and in epidemiological studies comparing different subject populations.

In order to control for inspiratory flow rate, the present authors recommend the use of a compressed air-driven nebuliser (model 646; DeVilbiss Health Care, Inc., Somerset, PA, USA) controlled by a dosimeter (KoKo DigiDoser; nSpire health Inc, Louisville, CO, USA (formerly Ferraris Respiratory Inc) and nSpire health Ltd, Hertford, UK (formerly Ferraris Respiratory Europe) that is modified by the addition of an inspiratory flow regulator valve (RIFR; nSpire health Inc, Louisville, CO, USA, formerly PDS Instrumentation, Inc). The valve limits inspiratory flow rate to $0.5 \mathrm{~L} \cdot \mathrm{s}^{-1}$ regardless of excessive inspiratory force, thereby guaranteeing a consistent and reproducible inspiratory effort with each breath. Thus, with appropriate instruction to inhale with sufficient force, all subjects achieve an identical inspiratory flow rate during each inhalation of aerosol.

\section{Nebuliser characteristics}

Significant variation in the amount of aerosol delivered per inhalation may occur with a standard nebuliser, even in an individual subject who attempts to maintain a constant inspiratory flow rate. The second major determinant of aerosol output is related to the structure of the nebuliser itself. For example, in the DeVilbiss 646 model, the straw and baffle assembly is a removable component of the nebuliser. When this structure is detached for washing and then reattached, variable distances result between the straw and baffle assembly and the source of pressurised air, the jet orifice. This variation in distance, albeit minute, results in variation in nebuliser output. Therefore, in order to optimise reproducibility, two modifications to a nebuliser are suggested. First, an inspiratory flow regulator valve is installed, as described above. Secondly, the straw and baffle assembly of the nebuliser is welded in place, thereby eliminating the variations in nebuliser output that may occur when these components are separated and then reattached with resulting variable distances between the jet orifice and straw. After these modifications are performed, the exact output (in $\mathrm{mL} \cdot \mathrm{min}^{-1}$ ) of the nebuliser is determined (characterised nebuliser; nSpire Health Inc, formerly PDS Instrumentation, Inc.). When the exact output of a nebuliser is known, modulation of the duration of aerosol delivery permits the determination of aerosol output per inhalation. For example, a nebuliser with an output of $1.007 \mathrm{~mL} \cdot \mathrm{min}^{-1}$, programmed to deliver aerosol for $1.2 \mathrm{~s}$, provides $0.02 \mathrm{~mL} \cdot \mathrm{breath}^{-1}$.

Given the potential variations in nebuliser output, it is essential that research investigations utilise equipment tailored to optimise reproducibility, and that the same nebuliser, or one with identical output, is used in studies incorporating serial cough challenges in individual subjects, or studies comparing distinct subject populations. Given the reality that different types of equipment will continue to be used by cough researchers worldwide, it is recommended that standardisation of cough challenge studies should be attempted by controlling nebuliser output per breath.

\section{Placebo inhalations}

In order to increase cough challenge blindness, inhalations of physiological saline (placebo) should be randomly interspersed 
between incremental concentrations of capsaicin and citric acid [25, 29]. This strategy may reduce the effects of voluntary suppression or conditioned responses in subjects who would otherwise be anticipating progressively higher concentrations of tussive agent.

\section{Instructions to subjects}

Subjects undergoing cough challenge should be specifically instructed not to attempt to suppress any coughs and not to talk immediately after inhalation of tussive agent, since this may potentially suppress cough. The present authors recommend, for example, the following instruction to subjects: "allow yourself to cough if you need to, and as much as you need to". Subjects should not be told that the induction of a specific number of coughs is the end-point of the study (see Interpretation of cough challenge data section) [11].

\section{Determination of tussive response to cough challenge}

When employing the single-breath method of capsaicin and citric acid administration, the tussive response to each dose of aerosol is immediate and brief. Therefore, only coughs occurring within $15 \mathrm{~s}$ of capsaicin and citric acid delivery should be counted [10, 25, 30, 31]. Coughs that occur beyond this time period may not be capsaicin or citric acid induced.

\section{Interpretation of cough challenge data}

For each test, the concentrations of capsaicin or citric acid causing two $\left(\mathrm{C}_{2}\right)$ and five coughs $\left(\mathrm{C}_{5}\right)$ are reported. The $\mathrm{C}_{2}$ and C5 can be obtained by determining the first administered concentration that results in two or more and five or more coughs, or by interpolation of logarithmically transformed concentration-response curve data. Overall, there are minor differences between these two methods [32]. Interpolated concentrations are closer to the real $\mathrm{C}_{2}$ and $\mathrm{C}_{5}$, but offer no particular advantage over the first administered concentration method. Differing opinions exist among investigators as to which is the preferred primary end-point, C2 or C5. Published studies often report both values, but not infrequently $\mathrm{C} 5$ alone is reported. There is evidence that $\mathrm{C}_{5}$ may be the clinically superior value [11], although other studies have found $C_{2}$ to be more reproducible [29]. Until further data are available, the present authors would recommend that both $\mathrm{C}_{2}$ and $\mathrm{C} 5$ are measured.

A potential problem in serial cough challenges involves the startle phenomenon [11]. A naive subject undergoing cough challenge may cough excessively, a phenomenon described with citric acid in the 1950s [16]. A preliminary familiarisation challenge may be required, or the $C 5$ may be used, since it is less likely to succumb to this potential pitfall.

A small subgroup of individuals with relatively high cough thresholds may not be able to achieve C5 despite using the highest concentrations of tussigen. The inhalation of high concentrations of capsaicin is precluded by a strong burning sensation in the upper airway, whereas citric acid inhalation may provoke a choking sensation or pharyngeal discomfort [18]. The present authors recommend that such subjects be excluded from comparative clinical trials because a true $\mathrm{C}_{5}$ cannot be discerned, and that the $\mathrm{C} 2$ is used in population studies.
Significance of capsaicin and citric acid cough sensitivity measurements

Isolated measurements of capsaicin sensitivity ( $\mathrm{C} 2$ or $\mathrm{C} 5)$ have no intrinsic significance due to the large variation in cough reflex sensitivity within the normal population (fig. 1). This contrasts with the assessment of bronchial responsiveness, where a provocative concentration of drug causing a $20 \%$ fall in forced expiratory volume in one second (FEV1) outside the normal range is predictive of pathophysiology [34]. Nevertheless, since cough reflex sensitivity to inhaled capsaicin and citric acid is highly reproducible when performed by a individual investigator or laboratory using appropriate methodology [11, 16-18, 25], these challenges have established themselves as an important tool in pharmacological studies incorporating serial challenges, as well as in epidemiological studies comparing distinct populations.

\section{Cleaning of the equipment}

The equipment should be sterilised between each subject. Sterilisation of the equipment should be performed in accordance with the individual institution's guidelines. For example, the present authors' protocol includes sterilisation for $15 \mathrm{~min}$ in Pera ${ }_{\circledR}$ Safe (Antec International, A DuPont Company, Sudbury, UK). Afterwards, the equipment is washed thoroughly with hot water and air dried.

\section{Tachyphylaxis and reproducibility}

Marked tachyphylaxis occurs to repeated cough challenge in the short term. Indeed, continual inhalation over $1 \mathrm{~min}$ of citric acid or capsaicin results in a reduction in cough frequency of a third with capsaicin and complete abrogation with citric acid. Repeated single-breath cough challenge at 10-min intervals similarly results in marked tachyphylaxis [35]. The present authors recommend a minimum of $1 \mathrm{~h}$, and preferably $2 \mathrm{~h}$, between cough challenge measurements. The high degree of long-term reproducibility of capsaicin and citric acid cough challenge testing has been reported by numerous investigators

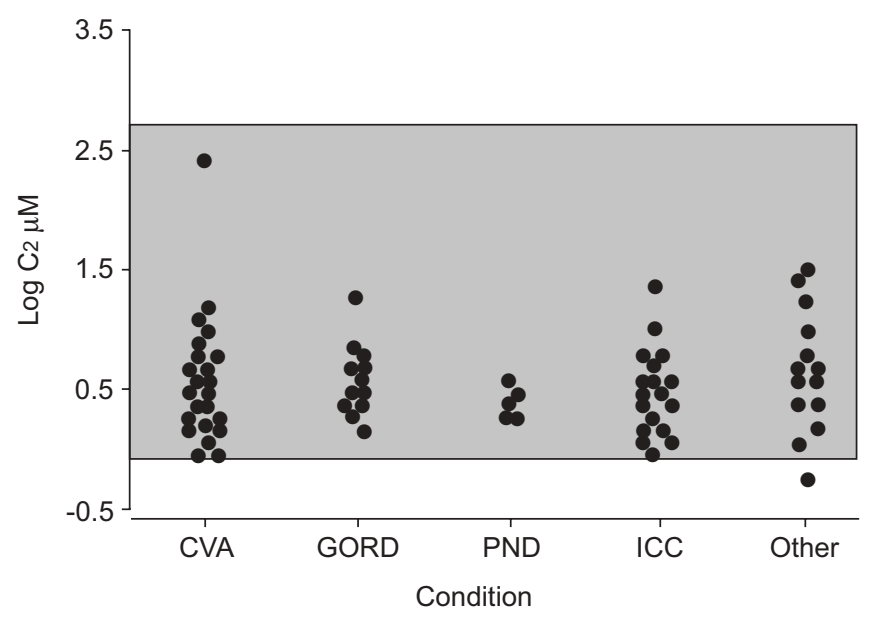

FIGURE 1. Cough reflex sensitivity to capsaicin in patients with chronic cough (: normal range (derived from 134 healthy subjects)). C2: concentration of capsaicin inducing two coughs; CVA: cough variant asthma; GORD: gastrooesophageal reflux disease; PND: post-nasal drip (rhinitis); ICC: idiopathic chronic cough; Other: chronic obstructive pulmonary disease, sarcoidosis, cryptogenic fibrosing alveolitis, and bronchiectasis. Adapted from [33]. 
employing the dose-response method and the single dose, with both the single-breath technique $[11,16,17,26,29,33,36-$ 41] and a fixed time period of capsaicin and citric acid inhalation [15-18, 26, 35, 42, 43].

Two studies have confirmed the reproducibility of capsaicin cough challenge over 3 months [44] and $>6$ months [11]. The latter demonstrated good reproducibility of cough challenge in 40 healthy volunteers at a mean interval of 16.7 months. The reproducibility of the recommended citric acid challenge has recently been demonstrated [45].

\section{Safety}

A recent review of the 20-yr clinical experience with capsaicin failed to uncover a single serious adverse event associated with capsaicin cough challenge testing in humans [46]. This review included an examination of 122 studies published since 1984, describing 4,833 subjects, including healthy adults and children, as well as patients with pathological cough, asthma, COPD, hypertension, gastro-oesophageal reflux disease, interstitial lung disease, acute upper respiratory tract infection, cervical spinal cord injury, heart-lung transplantation and cystic fibrosis [46]. Side-effects consisted mainly of transient throat irritation in a minority of subjects.

The safety of citric acid inhalation cough challenge was reported in the 1950s [16, 17]. However, inhalation cough challenge using citric acid can result in a small reduction in FEV1 $(<5 \%)$, which is unlikely to be of clinical significance [10]. Capsaicin does not induce clinically significant bronchoconstriction in healthy volunteers or asthmatics [15, 47].

However, the present authors would recommend that, when performing inhalation cough challenge, bronchodilator therapy be available.

Female healthy volunteers and female patients with chronic cough exhibit increased cough reflex sensitivity to capsaicin $[48,49]$ and citric and tartaric acid [22, 50, 51].

The placebo cough response shows a nonlinear increase in cough suppression, which is most pronounced at $4 \mathrm{~h}$ [40]. In addition, there are suggestions that females may cough more frequently and exhibit more rapid adaptation of cough than males.

The contact details of investigators experienced in these techniques can be found on the International Society for the Study of Cough website [52].

\section{Further research}

At present no data are available regarding the short- and longterm reproducibility of the above-mentioned method of citric acid inhalation cough challenge; however, they are currently being investigated. The amount of information available regarding the reproducibility of all cough challenge methods needs to be increased.

\section{Recommendations}

1) The methodology for the performance of inhalation cough challenge should be standardised so as to facilitate universal interpretation and comparison of data generated by different laboratories.
2) Comprehensive normal ranges need to be developed using the standardised methodology advocated in the present document.

3) The single-breath concentration-response method using a flow-limited dosimeter is recommended for most experimental protocols.

4) Both $C_{2}$ and $C 5$ should be recorded.

5) Since there is wide inter-individual variation, cough challenge data have no intrinsic significance, but may usefully be used to follow change in cough reflex sensitivity in an individual.

\section{COUGH INDUCED BY INHALATION OF AQUEOUS SOLUTIONS}

In order to evoke cough and other reflex respiratory responses using aerosolised aqueous solutions, the use of an ultrasonic nebuliser is mandatory. There are no reports regarding such responses being obtained using aerosols produced by conventional nebulisers. The technical features and principle of operation of most widely used ultrasonic nebulisers have been reviewed elsewhere [53,54]. Ultrasonic nebulisers generally produce a much larger solution output per unit volume of air than conventional nebulisers [53]. Since the tussigenic stimulus of any aqueous solution is caused by the reduced concentration of permeant anion, particularly chloride [55], any solution with a low permeant anion concentration can be used as a coughstimulating agent.

\section{Aerosol delivery}

Water aerosols are best delivered during tidal breathing; the use of a two-way valve $[55,56]$ or an outlet proximal to the subject's airway $[57,58]$ is required to avoid rebreathing. In order to ensure constant supply, the aerosol should be conveyed to a 1.5-2.0-L reservoir bottle [57].

\section{Dosing schedule}

Challenges with nebulised aqueous solutions can be performed according to two different methods, the single-dose and the dose-response method. In the first case, the nebuliser is set at a predetermined power output (usually the maximum attainable) and the nebulised agent is inhaled for a predetermined period (usually $1 \mathrm{~min}$ ) [35, 59-62]. Dose-response challenges can be performed by the subject inhaling stimuli of progressively higher intensity, obtained by increasing the nebuliser output in steps (fig. 2), each corresponding to a definite fraction of the maximum available output [55, 57]. Alternatively, the stimulus strength can be augmented progressively with constant nebuliser output, using nebulising solutions that are progressively lower in anion concentration [61-63].

\section{Outcome measure/sensitivity}

In single-dose challenges, the cough response is assessed in terms of cough frequency [35, 59-62]; however, cough frequency seems to be affected by some degree of stimulus adaptation [35]. In dose-response challenges, cough sensitivity can be evaluated as the cough threshold, i.e. the lowest stimulus intensity capable of evoking at least one cough during two dose-response challenges separated by a 30-min interval [56-58]. The reliability of other outcome measures, such as $\mathrm{C}_{2}$ 


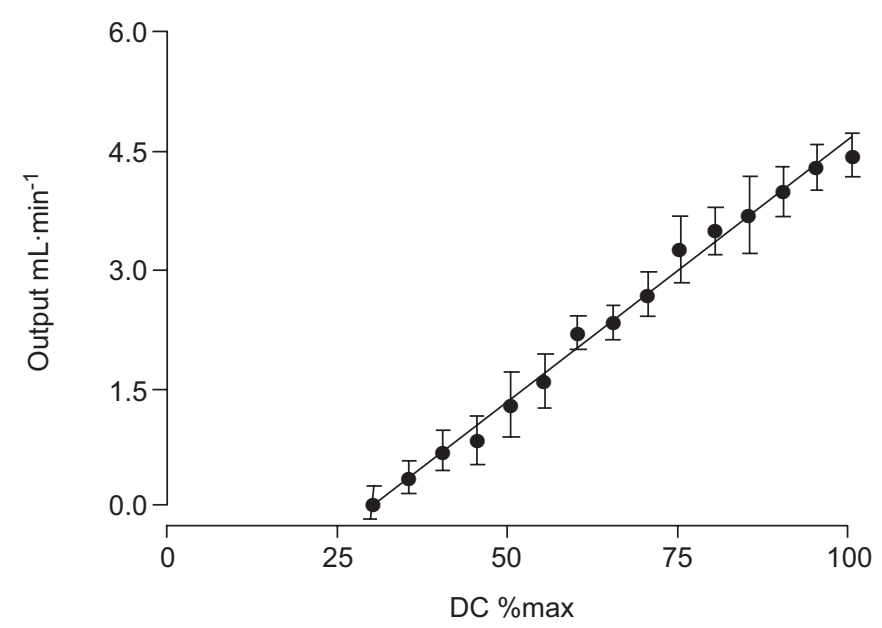

FIGURE 2. Relationship between ultrasonic nebuliser output $(y)$ and the corresponding direct current (DC) signal $(x)$ analysed using the least squares regression method. Data are presented as mean $\pm \mathrm{SD}$. The relation fits the linear model ( $r=0.95 ; p<0.001)$, and mean nebuliser output can be calculated from the following equation (using units shown): $y=-1.90+0.066 x$. The range of outputs (means) usually employed is $0.08-4.45 \mathrm{~mL} \cdot \mathrm{min}^{-1}$, i.e. $30-100 \%$ of the maximum DC signal.

and $\mathrm{C} 5$, i.e. the lowest stimulus intensity capable of evoking at least two or five coughs, has not been assessed using water aerosols. Quantitative measures, such as cough expiratory flow $[57,64]$ and the force developed by the expiratory muscles during single cough efforts [56-58, 64], may be useful when the intensity of motor responses needs to be evaluated.

\section{Reproducibility}

Several studies have established the reproducibility of cough sensitivity $[35,57,63-65]$ and cough intensity $[57,66]$ in doseresponse challenges using ultrasonically nebulised distilled water $[35,57,66]$ and other aqueous solutions $[63,65]$.

\section{Safety}

Ultrasonic nebulisers are obviously not disposable, and are expensive. Sterilisation of the equipment is, therefore, recommended at every use. This is potentially a major limitation to the use of ultrasonically nebulised aerosols outside the research field. Furthermore, hypotonic aerosols are potentially bronchoconstrictive in susceptible individuals [55].

Cough challenges with aqueous aerosols, however, present some features that may potentially be useful in cough research. The stimulus intensity can be increased in small fractional amounts, such that the cough threshold is assessed relatively precisely. In addition, since aqueous aerosols are inhaled during quiet relaxed breathing, it is possible to record several breathing pattern variables simultaneously, and thus investigate the ventilatory adjustments that may be evoked by airway receptor stimulation.

\section{Areas for future research}

Sensory receptor stimulation by fog may be due to both the absence of chloride ions (causing cough) and the hypoosmolarity (causing bronchoconstriction in susceptible individuals). Which of these fog-related stimuli is also responsible for fog-induced changes in the pattern of breathing remains to be established. The feasibility and reproducibility of measures such as $\mathrm{C}_{2}$ and $\mathrm{C}_{5}$ for the assessment of cough sensitivity to aqueous aerosols also needs to be determined.

\section{Recommendations}

1) Aerosolised aqueous solutions represent a useful experimental tool in cough research.

2) Ultrasonic distilled water (fog) challenge is difficult to standardise since it is highly dependent upon nebuliser output.

3) Consideration should be given to potential adverse events, such as bronchoconstriction and cross-infection.

\section{COUGH MONITORS}

Since the 1950s, researchers have been attempting to objectively measure cough [67-69], i.e. to quantify the amount of coughing per unit time. Although sound recordings can be made and cough events counted manually, this process is extremely laborious. Currently, no standardised method exists, and there is no adequately validated generic cough monitor that is commercially available and clinically acceptable.

An objective measure of cough would be of use in clinical practice, clinical research and the assessment of novel therapies. It would permit validation of the presence of cough, grading of severity and monitoring of responses to therapeutic trials. This is an exciting area of cough research and progress is being made. Various systems are being developed to automate cough identification and quantification, taking advantage of recent technological advances.

The present guidelines aim to inform both developers and potential users of cough monitors by highlighting the essential features of an ideal device and clarifying the appropriate methods for reporting on the performance of cough monitors.

\section{Nonambulatory methods of cough recording}

The very first cough monitoring systems to be developed were nonambulatory; mains-supplied tape recorders with free-field microphones were used to measure cough in hospital inpatients or study subjects overnight $[67,70]$. Similar systems can be used for documenting coughing in cough challenge studies.

\section{Ambulatory methods of cough recording}

The most useful systems are ambulatory and can count cough over a defined period of time (usually $24 \mathrm{~h}$ ). Advances in computing and digital storage media have permitted the use of digital sound recordings. Accurate recognition of the cough signal remains the limiting step and has been difficult to achieve. Several groups have applied digital signal processing techniques to cough sound recordings, but with limited success [71-74]. Hence, most systems still use manual counting, which is tedious and limits the size and scope of studies.

To date, more than six different systems have been described that rely on identification of the cough sound [72, 73, 75-79]. One of the first 24-h ambulatory systems used a solid-state multiple-channel recorder to measure the number of coughs [75]. Coughs were identified by the simultaneous occurrence of a digitised cough sound and an electromyographic signal from 
the respiratory muscles. The signals were analysed visually and counted manually.

Another system transmitted cough sounds from a microphone to a computer in the subject's home using telemetry [77]. Digitally stored coughs were counted manually, and also the cough latency (period between coughs), cough effort (integral of the acoustic power spectrum), cough intensity (cough effort divided by cough count) and cough wetness were measured.

In one cough recording system, cough was quantified in terms of the amount of time spent coughing, i.e. the number of seconds containing at least one explosive cough [78, 80, 81]. This was used to obtain a more encompassing definition of cough rather than just measuring the explosive component that can be heard.

In terms of automation of the cough recognition system, MORICE and WALMSLEY [73] described a probabilistic neural network system for differentiating cough from noncough. Using a Sony Walkman digital audio tape recorder (Sony, Malaysia), it was demonstrated that this system recorded similar numbers of coughs to manual counting.

BIRRING and co-workers $[82,83]$ developed the Leicester Cough Monitor, which detects coughs in patients with chronic dry cough using a statistical model and quantifies coughs as individual events.

Using an ambulatory cardiorespiratory monitoring system (LifeShirt; Vivometrics, Nahant, MA, USA) with an integrated unidirectional contact microphone, cough was measured in eight COPD patients under laboratory conditions and automatically counted using statistical parameters [79]. Compared with cough counts from video and sound recording, good correlation was obtained.

\section{Defining cough}

Coughing produces a characteristic sound [84]. The sound results from rapid changes in airflow generated by the contractions of muscles in the chest wall, abdomen, diaphragm and larynx. Hence a variety of modalities can be used to detect coughing (table 2). The definition of a cough depends upon the signal(s) monitored. Cough counting using sound either alone or in combination with a second signal has been most commonly used $[75,76,79,85]$, and the phases of a typical cough sound are shown in figure 3 . It is essential that any cough monitoring device defines exactly what is recognised as a cough, from which signal(s) and, furthermore, how coughing is quantified.

TABLE 2 Signals and sensor types for monitoring cough

\begin{tabular}{lc} 
& Sensor \\
\hline Sound & Free-field microphone \\
& Air-coupled microphone \\
Movement & Contact microphone \\
& Electromyography \\
& Accelerometer \\
& Induction plethysmography \\
\hline
\end{tabular}

\section{Quantification of coughing}

One of the difficulties in identifying and quantifying cough is that a variety of patterns of coughing occur. If the sound signal is examined, three main patterns have been consistently described in the literature (figs 3-5) [84, 86, 87], but many more exist. Coughing can be quantified in a number of different ways. Figure 6 shows a short sound recording of coughing and four possible methods of quantification as follows. 1) Explosive cough sounds (fig. 6a); counting the characteristic explosive cough sounds is the most intuitive way of counting cough. 2) Cough seconds (fig. 6b); this is a measure of the time spent coughing, i.e. the number of seconds per hour containing at least one explosive cough sound. 3) Cough breaths (fig. 6c); these are used in a system that continuously monitors breathing and quantifies cough as the number of breaths which contain at least one explosive cough sound. 4) Cough epochs (fig. 6d); continuous coughing sounds without a 2-s pause are counted.

Whether any of these methods is more valid than any other is not known, but it is fundamental to describe the unit of cough used. There is a tight linear relationship between cough sounds and cough seconds in a variety of conditions (fig. 7).

\section{Other end-points in cough monitoring}

Other features of the cough signal apart from the number of coughs are potentially of use as clinical end-points, as follows. 1) The intensity of coughing is likely to be important; subjects with a small number of coughs may still find the symptom very distressing if associated with chest pains, retching or syncope. Both the peak intensity achieved and the overall energy released in coughs may be valuable measures. 2) The pattern of coughing (peals versus single coughs) may not only affect the patient's experience but also serve different mechanical purposes. Furthermore, the rates of coughing throughout the day and night may be related to the stimulus to cough [81]. 3) The acoustic properties of the cough sounds are of potential use in identifying the presence of airway secretions or wheeze.

Automated identification of coughs is necessary to facilitate the study of these additional parameters. Ambulatory monitoring over $24 \mathrm{~h}$ in the patient's own environment is necessary as cough rates can change from hour to hour, show diurnal variation and may be affected by a nonambulatory setting.

\section{Validation of cough monitors}

Validation of cough monitors against a gold standard measure is obligatory. Manual cough counting from video or sound recordings is used, and, although extremely laborious [79, 88], good agreement between observers has been achieved.

Video recordings have the advantage that the movements associated with coughing can be seen, but monitoring has to be restricted to the area in view of the camera. It cannot be assumed that performance is the same in a fully ambulatory subject. Validation of ambulatory cough monitoring is possible using a small digital sound recorder and microphone running simultaneously with the cough monitor [71].

Additionally, the acoustic properties of cough sounds vary in different diseases [87,89]; thus validity in one patient group is not generalisable. Cough detection should therefore be 


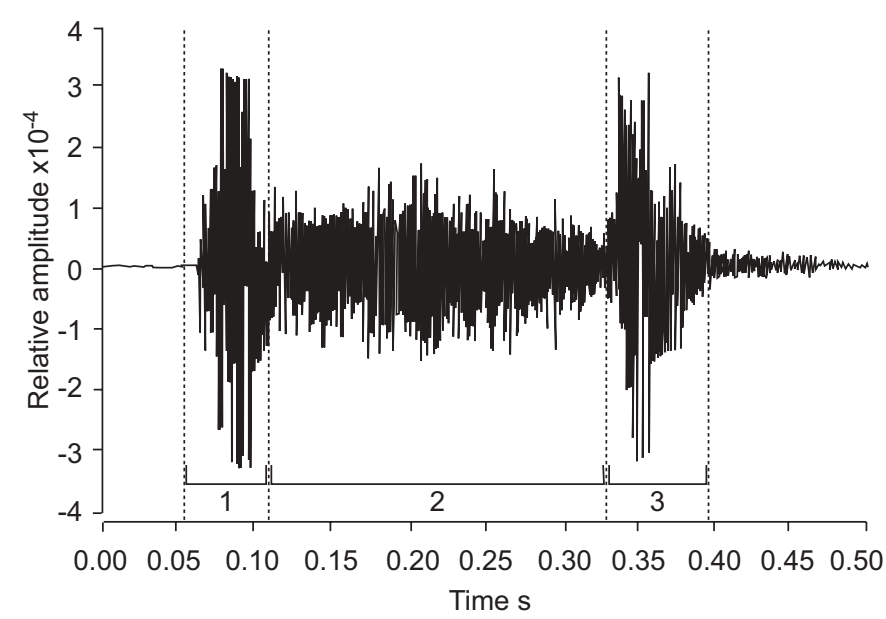

FIGURE 3. Three-phase cough sound (1: explosive phase; 2: intermediate phase; 3: voiced phase)

validated in patients with chronic cough (with a range of aetiologies) and cough in other respiratory conditions.

\section{Sensitivity and specificity}

Sensitivity, specificity and positive and negative predictive values contribute to a description of cough monitor performance. As sounds that could be mistaken for cough (e.g. speech, throat clearing, laughing and sneezing) may occur more often than coughs, the number and nature of false positive results should also be reported. Agreement between manual and automated cough counts [90] gives a clear representation as to how much the two measures differ and whether this difference is related to the magnitude of the measurement. The reproducibility of the performance of the cough monitor and responsiveness to change are also important attributes. The precision of all of these measures (i.e. $95 \%$ confidence intervals) permits assessment of the consistency of performance.

\section{Future work in cough monitoring}

There has been very significant progress towards fully automated cough counting in recent years, but testing of the performance of systems needs to be rigorous. Accurate cough counters will add a new dimension to cough assessment. Simple cough counts are, however, only one dimension of cough, and probably explain only part of the patient's experiences of the symptom. Further end-points, such as cough intensity, coughing patterns over both the short and long term, and acoustic parameters (representing wheeze and airway secretions), are wide open for development and investigation.

\section{Recommendations}

1) No cough monitor is currently the gold standard.

2) Monitors should be developed that are ambulatory, capable of being digitally processed and permit prolonged (24-h) recording.

3) There is little to commend any particular method of quantifying cough over any other.

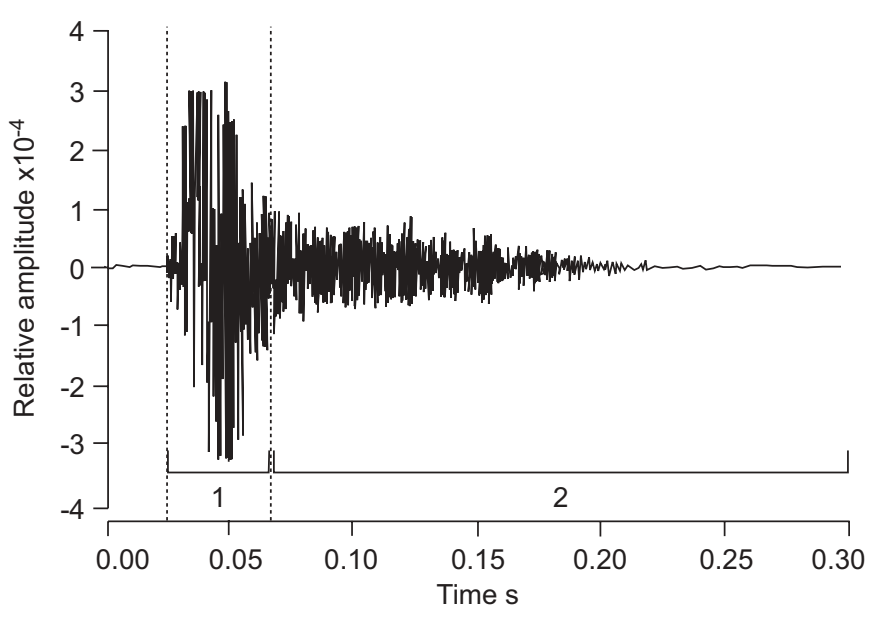

FIGURE 4. Two-phase cough sound (1: explosive phase; 2: intermediate phase)

\section{ASSESSMENT OF QUALITY OF LIFE OF PATIENTS WITH CHRONIC COUGH}

Chronic cough is often perceived as a trivial problem, but can be a disabling symptom associated with significantly impaired quality of life [8,9]. Until recently, there have been no tools for measuring cough-specific quality of life. Indeed, there is a striking paucity of well-validated outcome measures in chronic cough. There is no consensus regarding the definition of health-related quality of life, but the World Health Organization definition of health as "a state of complete physical, mental and social well-being, and not merely the absence of disease" is widely quoted [91]. Health status or health-related quality-of-life measurement is a means of quantifying the impact of disease or symptoms on patients' daily life and general well-being in a standardised and objective manner. Quality-of-life questionnaires are widely used in clinical studies and are standard end-points in most randomised controlled trials. This section focuses on the effects of chronic cough on health status and the measurement of quality of life in patients with chronic cough.

\section{Adverse impact of cough on health status}

Cough has wide-ranging effects on health status. The reasons why patients with chronic cough seek medical advice are poorly understood, but may relate to worry about the cough, embarrassment, self-consciousness and the presence of associated symptoms, such as nausea and exhaustion [92]. In acute cough, health status is impaired transiently. The impact of chronic cough on health status is varied, being minimal in some patients who do not seek medical attention to disabling in others, associated with impairment of quality of life comparable to that in other chronic respiratory disorders, such as COPD. The physical, psychological and social domains of health are commonly affected [9]. Patients with chronic cough frequently report musculoskeletal chest pains, sleep disturbance and hoarse voice. More marked symptoms, such as blackouts, stress incontinence and vomiting can occur. Some patients report adverse symptoms related to the urge and sensation to cough and the act of cough suppression. The psychological aspects of health status affected often include worry about serious underlying diseases, such as cancer and 


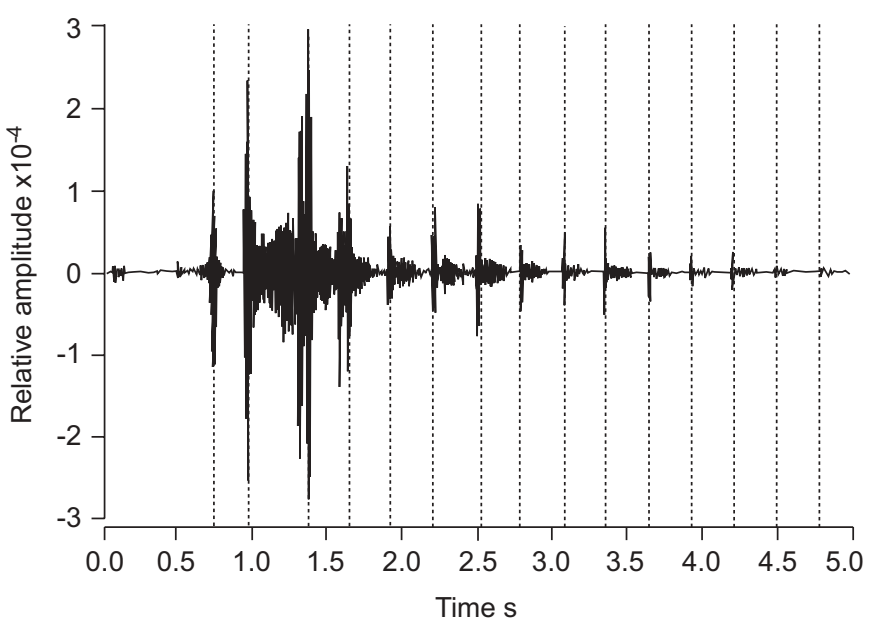

FIGURE 5. Peal of coughs after a single inspiration with repeated explosive phases (……...).

tuberculosis. The impact of cough on social well-being depends upon individual circumstances. The cough may result in difficulty in relationships, avoidance of public places, disruption at work and, in severe cases, time off work. The wide-ranging and potentially profound effects of cough on health status highlight the importance of a detailed history of associated symptoms and concerns when assessing a patient with chronic cough.

\section{Assessment of health status}

Cough scores, diaries and visual analogue scales

Cough scores [93], diaries [27, 94, 95], symptom questionnaires $[96,97]$ and visual analogue scales (VASs) [98] are commonly used in clinical studies to evaluate cough severity, but all lack thorough validation for this purpose. Most symptom-based tools include questions relating to cough frequency, but probably measure a combination of aspects of cough severity that encompass cough frequency and intensity, mood and quality of life. Very little is known about their relationship to other parameters of cough severity, such as objective cough frequency and cough reflex sensitivity. Unlike quality-of-life questionnaires, the different components of health status cannot be identified from cough diaries and VASs.

Cough diaries comprise questions relating to cough frequency [75]. They correlate weakly with objectively measured daytime cough frequency and there is no relationship with nocturnal cough counts [75]. The reproducibility and responsiveness of cough diaries has not been reported and their relationship to other parameters of cough severity, such as cough reflex sensitivity, is not known for patients with chronic cough. In children, the reproducibility of parent-completed cough symptom questionnaires is poor [97]. Self-completed cough diaries for children show good responsiveness and correlate better with objective cough frequency [94]. Interestingly, in children, self-completed cough diaries relate better to objective cough frequency than those completed by their parents [94].

Cough VASs are 100-mm linear scales on which patients indicate the severity of their cough; $0 \mathrm{~mm}$ represents no cough and $100 \mathrm{~mm}$ the worst cough ever (fig. 8). It is important that patients receive clear instructions regarding the time period during which cough severity is being assessed. Cough VAS score is highly repeatable over a 2-week period in patients with cough due to COPD (within-subject SD $7.8 \mathrm{~mm}$; intra-class correlation coefficient 0.87) [99]. Cough VAS score is also highly responsive when used as an outcome measure in clinical studies of patients with a chronic cough [9, 100, 101]. Cough VAS score relates well to cough-specific quality of life, but not to cough reflex sensitivity [9]. Its relationship to objective cough frequency is not known.

\section{Quality-of-life questionnaires}

Quality-of-life measures can be used to facilitate communication with patients and establish information regarding the range of problems affecting them. The impact of illness on health and treatment preferences often differ between patient and physician, and, therefore, quality-of-life considerations should take the patient's perspective into account. The simplest method of assessing quality of life is to ask the patient [102]. Drawbacks to this are that some observers are poor judges of patients' opinions. Assessment of patients using quality-of-life instruments is essentially similar to a structured clinical history, although the outcome parameter is an objective, validated and quantifiable measurement. Qualityof-life domains are usually measured separately to assess emotional and psychological well-being, as well as the physical and practical aspects of daily life. Questionnaires can be generic or disease-specific. Generic instruments are intended for general use, irrespective of illness. Quality-of-life scores from patients can be compared with those in other conditions and even healthy subjects [103]. However, generic instruments lack specificity, do not focus on issues related to patients' conditions and are less responsive to specific interventions compared with disease-specific tools. This has led to the development of three cough-specific quality-of-life questionnaires for use in patients with chronic cough, the coughspecific quality-of-life questionnaire (CQLQ), Leicester Cough Questionnaire (LCQ) and Chronic Cough Impact Questionnaire (CCIQ) [8, 9, 104]

\section{Cough-specific quality-of-life questionnaire}

The CQLQ is a recently published 28-item questionnaire that has been developed and tested in North America [8]. It is intended for use in adults with acute and chronic cough. The questionnaire is self-completed and contains a four-point Likert response scale. The items are divided into six domains: physical complaints, extreme physical complaints, psychosocial issues, emotional well-being, personal safety fears and functional abilities. Items for this questionnaire were selected by the investigators and allocated to domains by factor analysis. Factor analysis is a psychometric method that is used to select and allocate items to domains and is based largely on the structure of correlations between items, although the investigators must make a number of subjective decisions throughout the process. Although commonly used in the development of quality-of-life questionnaires, a weakness of factor analysis is that it does not take into account the perception of the clinical relevance of items by the intended population. Concurrent validity, the comparison of an instrument against other standards that provide an indication of the true value for measurement, was assessed for a preliminary 


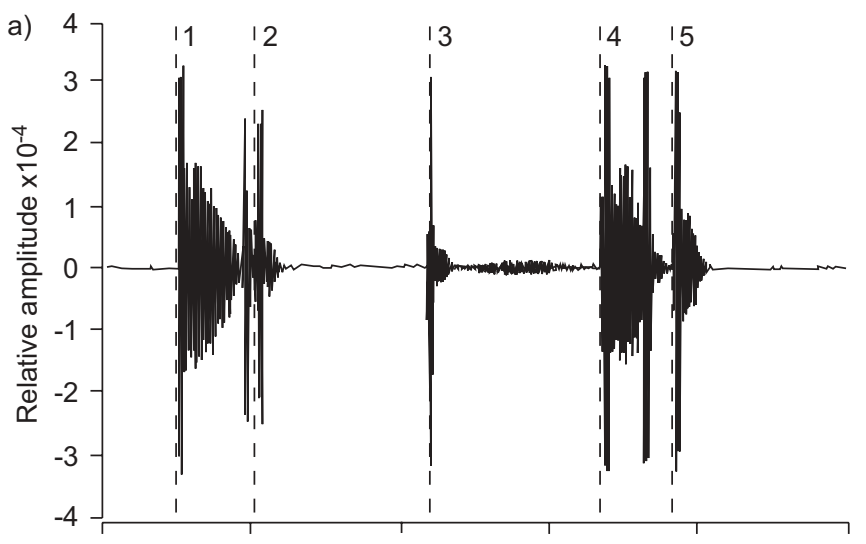

b)
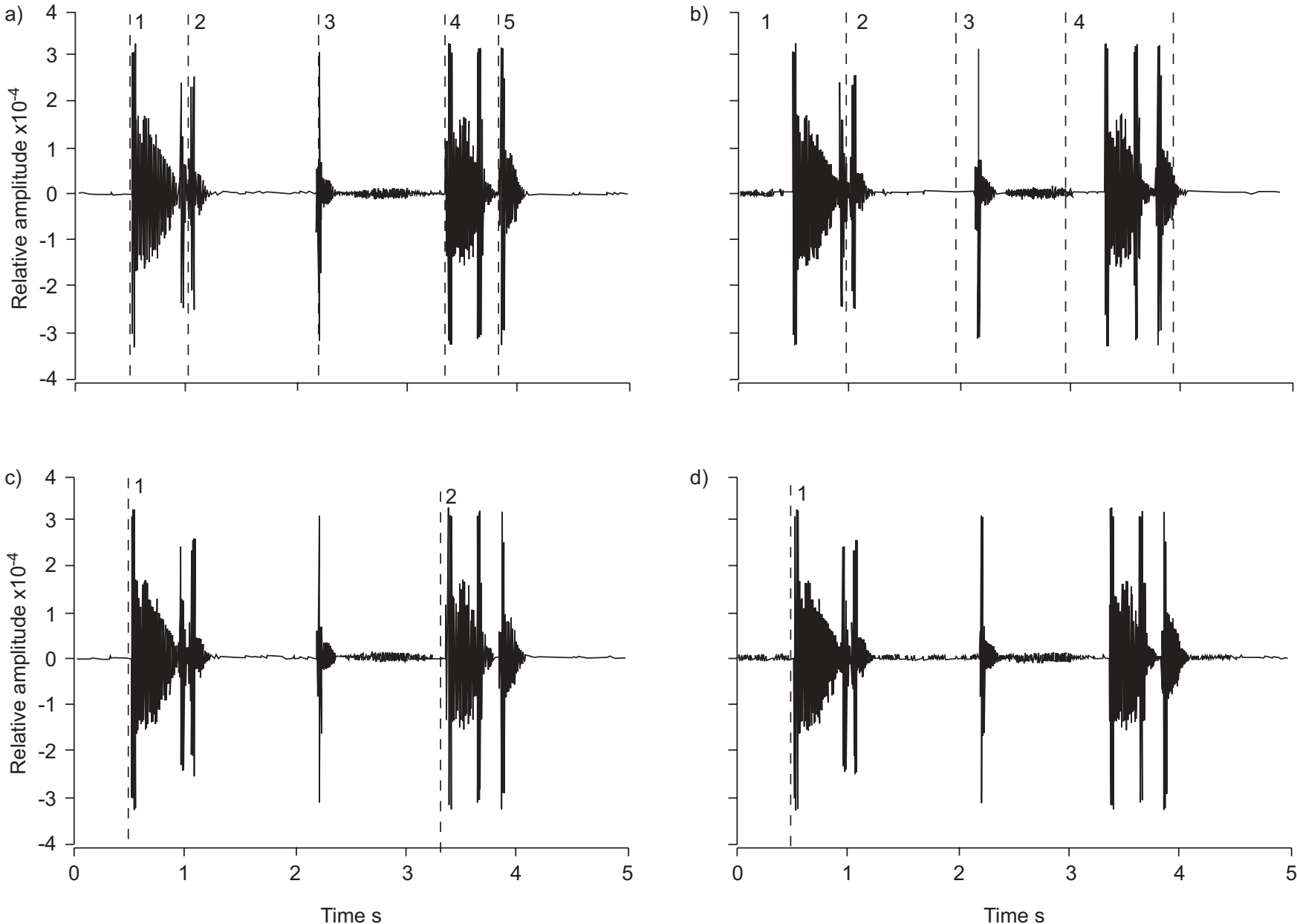

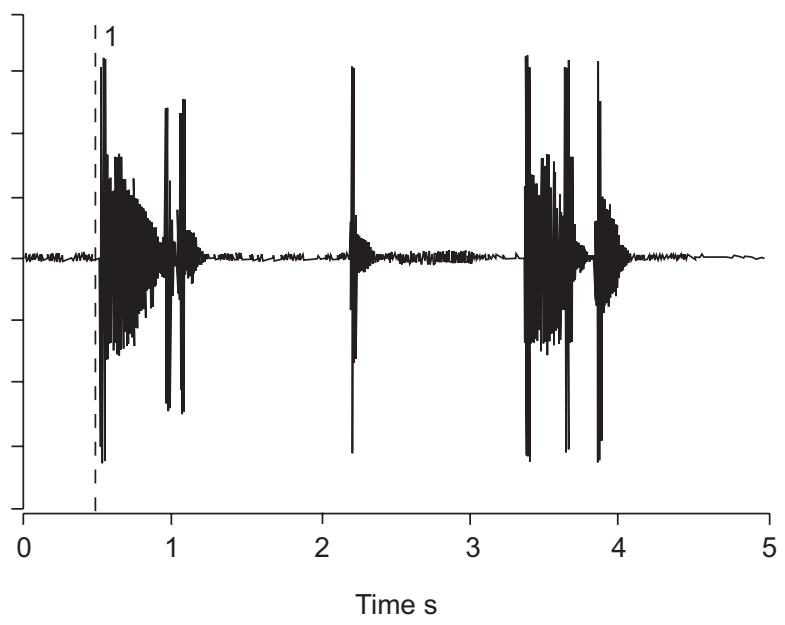

FIGURE 6. Various methods of quantifying coughing: a) explosive cough sounds; b) cough seconds; c) cough breaths; and d) cough epochs (---: units of cough counting; numbers represent cough count).

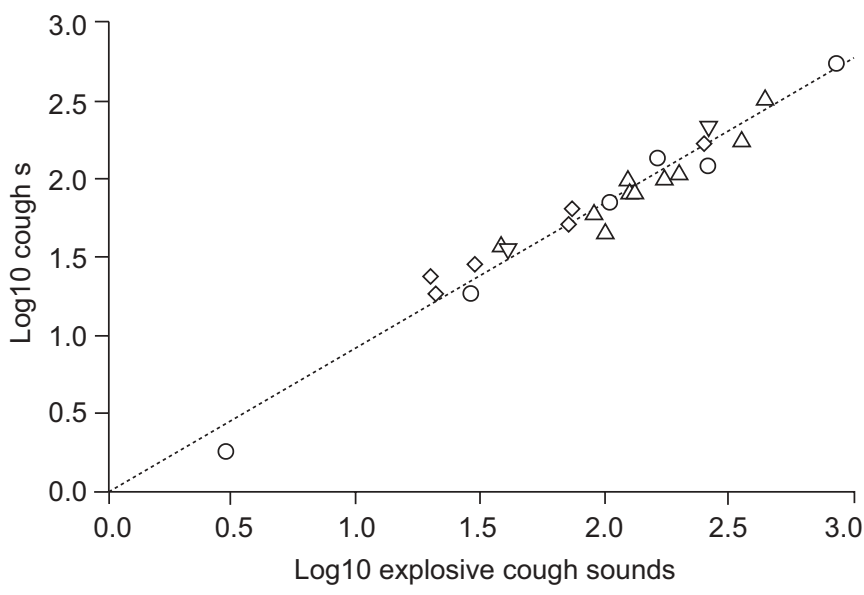

FIGURE 7. A comparison of cough quantification using cough seconds and explosive cough sounds in different diseases. $\triangle$ : cystic fibrosis; $\diamond$ : idiopathic pulmonary fibrosis; $\nabla$ : chronic obstructive pulmonary disease; $\bigcirc:$ asthma. .......... overall line of best fit. version of the CQLQ, called the Adverse Cough Outcome Survey (ACOS) [92]. The ACOS correlated moderately with a generic quality-of-life questionnaire (Sickness Impact Profile). The CQLQ is both repeatable and responsive to change in patients with chronic cough, but this was not tested for patients with acute cough. The relationship between CQLQ, cough reflex sensitivity and objective cough frequency is not known. Studies to determine the minimal important clinical difference are under way.

\section{Leicester Cough Questionnaire}

The LCQ is a brief, easy to administer and well-validated chronic cough health-related quality-of-life questionnaire developed in the UK [9]. The LCQ comprises 19 items and three domains (physical, psychological and social). The questionnaire is self-completed and contains a seven-point Likert response scale. One of the key differences between the LCQ and the CQLQ is that items for the LCQ were chosen using the clinical impact factor method. This method chooses items that patients label as a problem and ranks them by the importance associated to them. Items were categorised into domains using clinical sensibility. The LCQ was extensively validated against other quality-of-life questionnaires and 


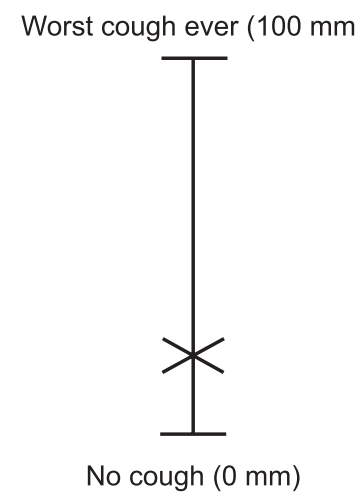

FIGURE 8. Cough visual analogue scale. Please put a cross on the line to indicate the severity of your cough in the last 2 weeks. (Not to scale.)

measures of cough severity [9]. The LCQ has been shown to be repeatable and responsive in patients with chronic cough and responsive in acute cough $[9,105]$. Preliminary data suggest that the LCQ correlates with objectively measured cough frequency in patients with chronic cough [82]. The minimal important clinical difference for patients with chronic cough is LCQ total score 1.3 [106]. A study to determine the minimal important clinical difference for patients with acute cough is under way. The LCQ has been a responsive tool when used as a primary outcome parameter in clinical trials of antitussive therapy for patients with chronic cough [107]. The LCQ can be obtained from the online version of [9].

\section{Chronic Cough Impact Questionnaire}

The CCIQ is the most recently described cough-specific quality-of-life measure, developed in Italy [104]. It comprises a 21-item questionnaire divided into four domains (sleep/ concentration, impact on relationship, impact on daily life and mood) and contains a five-point Likert response scale. The CCIQ is brief, simple to administer and validity has been tested in large numbers of patients. The published report describing the development of the CCIQ lacks important validation data [104]. The repeatability and responsiveness of the questionnaire are not reported, and the minimal important clinical difference and relationship to other markers of cough severity are not known.

\section{Health status in chronic cough}

Little is known about the effects of cough on health status. However, preliminary data from studies using cough-specific quality-of-life questionnaires afford an insight. Quality of life is significantly impaired in acute cough; this impairment affects males and females equally [108]. In patients with chronic cough, quality of life is impaired, to a greater extent in female patients compared with males [109] and not related to age, duration or aetiology [92, 110]. The psychological aspects of health status are particularly affected in patients with chronic cough, and there is a high prevalence of depressive symptoms [109-111]. There is good evidence that health status improves significantly after specific therapy for the cough $[8,9]$.

A recent study comparing a translated LCQ and CQLQ in Turkish patients with chronic cough found a moderate correlation between the questionnaires [112]. Both translated questionnaires showed good concurrent validity and responsiveness, which suggests that the LCQ and CQLQ may be adaptable for patients from a different cultural background.

\section{Conclusions}

Chronic cough can have profound effects on quality of life. Its management should include an assessment of health status. The LCQ, CQLQ and CCIQ are intended for use in adult patients with chronic cough. Quality-of-life questionnaires can be used to assess longitudinal changes in patients with chronic cough and identify the specific health domains affected. Quality-of-life questionnaires should be used to supplement objective markers of disease severity and assess the effectiveness of therapeutic interventions in the clinic and clinical trials, and be integral to cost utility analysis.

\section{Future research}

Further work is required to determine the minimal clinically important difference for cough health status questionnaires and investigate the relationship between quality of life and other markers of cough severity. Further clinical trials using cough-specific quality of life as outcome measure are awaited.

\section{Recommendations}

1) Cough can have profound effects on health status, which can be assessed by cough-specific health status questionnaires.

2) Cough VASs (0-100 mm) should be used to assess cough severity in patients with chronic cough.

3) Patients with chronic cough should be assessed with coughspecific quality-of-life questionnaires in clinical studies.

\section{ANIMAL MODELS OF COUGH}

Cough is a reflex defence mechanism and is a most common symptom of many inflammatory diseases of the airways [113]. At present, there are no satisfactory treatments for acute cough, as outlined in a recent review in which over-the-counter cough medicines were assessed [114]. Therefore, the search is on for possible novel antitussive therapies. However, prior to evaluation of such agents in humans, they must be tested in appropriate animal models. The ultimate goal of an animal model is to provide a system in which to elucidate mechanisms and test putative drug candidates. The model needs to be reliable, robust and reproducible and accurately reflect the disease in humans as closely as is possible.

\section{Species}

Most pre-clinical studies of neural pathways involved in the cough reflex and the pharmacological regulation of such pathways have been conducted in mice, rats, guinea pigs, rabbits, cats and dogs [115], as well as, more recently, in conscious pigs [116].

In rodents, the cough reflex is difficult to study in anaesthetised animals, since anaesthesia suppresses neuronal conduction and activity in the central nervous system (CNS). However, several investigators have used a conscious rat model of cough to study the effect of potential antitussive therapies. Although many studies have been performed in conscious rats and cough sounds recorded [117], there is much scepticism regarding the ability of these animals to produce a cough that resembles the reflex seen in humans. Indeed, it is 
thought that, if cough can be elicited in rats, the main reflexogenic origin of the cough is the larynx rather than the tracheobronchial tree [13]. Indeed, expulsive events originating from the larynx can include expiration reflexes, which are difficult to differentiate from cough. Furthermore, the two reflexes are regulated differently [118]. Other studies have described a murine model of cough [119], but again, certain reservations exist regarding the use of this model given that mice do not have rapidly adapting receptors (thought, along with C-fibre afferents, to play an important role in the cough reflex) and have been found to be lacking in intra-epithelial nerve endings and thus are thought to be without a cough reflex [119]. It has also been shown that mice cannot cough [13], as they cannot generate the energy needed to cough. It is, therefore, probable that investigators using the model are measuring an expiration reflex rather than a true cough.

The use of large animals, such as cats, dogs and pigs, involves a cost element with regard to not only their purchase price but also their feeding and housing and the production of large quantities of drug substance for screening purposes. Although the use of these animals is thus precluded for routine screening, they may be of value in tertiary screening.

The most useful and commonly used model for cough studies in recent years has been the conscious guinea pig [120, 121]. Much information has been gathered using this model regarding both the physiological [122] and the pharmacological modulation of the cough reflex. In these experiments, cough can be detected by putting the guinea pig in a transparent Perspex chamber, exposing it to aerosols of tussive stimuli and measuring changes in airflow, observing the characteristic posture of an animal about to cough and recording the cough sound [123-125].

\section{The guinea pig model of cough}

As stated above, the guinea pig is the most useful laboratory animal for experimental studies of chemically induced cough, compared with the rat and rabbit [126]. This animal has been utilised extensively, with cough being induced in conscious animals by inhalation of aerosols of either capsaicin or low $\mathrm{pH}$ solutions such as citric acid [10, 123, 127-129]. The guinea pig provides a good model of the human cough reflex, and this has been confirmed in a study showing the similarity in response to both citric acid and capsaicin in humans and the guinea pig [10]. Furthermore, recent in vitro data suggest that the isolated guinea pig vagus nerve depolarises in response to tussive stimuli in a similar manner to the isolated human vagus [130].

However, the guinea pig model differs from humans in certain respects. Although both guinea pigs and humans respond to capsaicin in a similar fashion in eliciting cough, capsaicin (and to a lesser extent citric acid) produces tachypnoea in guinea pigs [10]. Furthermore, if the local release of substance P from C-fibre nerve endings contributes in any way to the cough reflex, this may lead to differences in the cough reflex given the sparse population of neuropeptide-containing nerves in human airways. Furthermore, the guinea pig is an obligate nose breather, which may also introduce species differences in the cough reflex. Lastly, the demonstrated activity of certain development molecules with no demonstrated efficacy in humans in animal models has led to the suggestion that data generated from these systems may not be predictive of the situation in humans.

\section{Conscious versus anaesthetised animals}

In rodents, the cough reflex is difficult to study in anaesthetised animals since anaesthesia suppresses neuronal conduction and activity in the CNS. However, in some species, a suitable depth of anaesthesia, with essentially intact respiratory reflexes, can be obtained and a tussive response easily measured [115, 131, 132]. An example of this is the anaesthetised cat, which has been utilised to analyse both the central effects of antitussives administered intracerebroventricularly [133] and the peripheral effects of compounds administered intravenously [134]. In these experiments, cough in response to mechanical and chemical stimuli is characterised by a deep inspiration followed by an active expiratory effort. In other experiments, cough has been defined, in anaesthetised animals, as a large burst of electromyographic activity in the diaphragm immediately followed by a burst of activity in the rectus abdominus muscle [135]. Interestingly, data recently presented by CANNING et al. [131] demonstrated that capsaicin and bradykinin (C-fibre stimulants) are totally ineffective at initiating the cough reflex in anaesthetised guinea pigs even though the cough reflex initiated by mechanical stimuli (largely rapidly adapting receptor-selective) is entirely preserved in the anaesthetised state. Consistent with this data, TATAR and PECOVA [136] showed that, in urethane-anaesthetised guinea pigs, cough could be regularly elicited by mechanical stimulation of the larynx and tracheobronchial tree. Inhalation of a capsaicin aerosol did not change the respiratory pattern and did not elicit any cough. However, these chemical agents elicit a cough reflex in conscious guinea pigs. This suggests that anaesthesia is perhaps best avoided when studying the cough reflex in animal models.

\section{Methodology}

A procedure for measuring cough in conscious guinea pigs has been described [10, 120,124-127]. The guinea pig is placed in a small Perspex box ( $\sim 1 \mathrm{~L}$ in volume) that allows free movement during exposure to aerosols. Some investigators have used a double-chambered body plethysmograph with some success [137]. Airflow through the box is provided by compressed medical air via a flow regulator at $\sim 600 \mathrm{~mL} \cdot \mathrm{min}^{-1}$, with changes in airflow induced by respiration and coughing detected by a pneumotachograph, amplified via a pressure transducer and recorded on a chart recorder or computer. Cough sounds are amplified and recorded via a microphone sited in the cough chamber and recorded concurrently on the computer. Tussive agents (capsaicin, citric acid, etc.) are delivered by aerosol using an ultrasonic nebuliser, with an output of $\sim 0.4 \mathrm{~mL} \cdot \mathrm{min}^{-1}$ and delivering a median particle diameter of $\sim 1 \mu \mathrm{m}$, connected to the airflow port. The animal is exposed for a defined period, usually $\leqslant 10 \mathrm{~min}$, depending on the tussive agent used. A dose-response curve to the chosen stimulus should be constructed, and a submaximal dose chosen for further studies. Other protocols include using citric acid aerosol in gradually increasing concentrations $(0.05-$ $1.6 \mathrm{M})$, each for $30 \mathrm{~s}$. Cough is recorded during the $30-\mathrm{s}$ inhalation of each concentration of the tussigen and during the subsequent 60-s observation time. Therefore, the interval between exposures is $1.5 \mathrm{~min}$. The number of coughs elicited 
by each concentration is compared with a control group. When there are significant differences in cough numbers during inhalation of lower concentrations, it can be concluded that the cough sensitivity is changed [138].

It can be extremely difficult to differentiate cough from other upper airway reflexes. Therefore, coughs should be assessed and counted by a trained observer using three different methods in order to ensure that only coughs are counted and that sneezes and augmented breaths are excluded. The three methods are as follows. 1) Observation (or video recording) by an observer trained to differentiate between coughs and sneezes and to recognise the changes in posture (splaying of the front feet and forward stretching of the neck) and characteristic opening of the mouth associated with cough. 2) Pressure or airflow changes reflecting the deep inspiration and explosive expiration occurring during cough. 3) Sound, i.e. the characteristic sounds of a guinea pig cough. Results can be expressed as coughs per minute or coughs per 10 minutes, and comparisons made with vehicle-control-treated animals.

\section{Tussive stimuli}

The cough reflex can be elicited by electrical, mechanical (in anaesthetised animals) or chemical stimulation, as well as by changes in ion concentration or osmolarity in the mucosal surface fluid, of sensory afferents (in the larynx, trachea or bronchial mucosa) or by stimulation of the CNS. More recent studies have utilised the irritant capsaicin and low $\mathrm{pH}$ solutions (e.g. citric acid) to study the cough response. Citric acid confers the advantage of allowing repeated cough measurements without the occurrence of tachyphylaxis, whereas repeated exposure to capsaicin is known to result in tachyphylaxis, preventing the production of a reproducible cough response in the same animal $[25,138]$. Different methods of stimulation may involve different populations of sensory afferent, and there has been much discussion in the literature regarding the selectivity of agents for different fibre types, e.g. the use of capsaicin as a selective C-fibre stimulant [124, 139].

\section{Experimental design}

Animals should be housed under controlled conditions with frequent changes of bedding, as the build-up of ammonia in cages has been shown to influence the cough response to citric acid [140]. M.G. Belvisi and co-workers (unpublished data) have shown that the cough response to a given stimulus varies greatly from guinea pig to guinea pig, but that repeated assessments within the same animal are fairly reproducible with citric acid but not with capsaicin. Therefore, it is probably wise to perform experiments in separate animals with test group data compared with vehicle-treated animals rather than in the same animal before and after vehicle/drug treatment. However the inherent variability in conscious models suggests that large numbers, of between eight and 12, should be utilised in studies. The same authors have not found it necessary to precondition guinea pigs to accept aerosol exposure in the challenging box.

\section{Disease models}

It is now recognised that many pulmonary disorders are associated with enhanced cough. However, the mechanisms involved in these exaggerated responses are not known.

\section{Allergic models}

Most models have been configured in the guinea pig and have demonstrated increased coughing in response to capsaicin $\geqslant 1$ day after antigen challenge in sensitised animals [141, 142]. The increased tussive response is associated with eosinophilia. Tachykinins appear to play a role in the augmented cough response in allergic guinea pigs, since enhanced cough response to capsaicin, following antigen challenge, has been shown to be suppressed by neurokinin $(\mathrm{NK})_{1}$ and $\mathrm{NK}_{2}$ and dual $\left(\mathrm{NK}_{1} / \mathrm{NK}_{2}\right)$ receptor antagonists [141]. An enhanced cough response to mechanical stimulation of the trachea has also been seen in anaesthetised dogs sensitised and challenged with ragweed antigen [143].

\section{Models of post-nasal drip}

Chronic disorders of the nose and sinuses (e.g. allergic and nonallergic rhinitis, sinusitis and vasomotor rhinitis) are also common causes of chronic cough [7]. This phenomenon has been demonstrated in animal models in that stimulation of nasal afferents with capsaicin has been shown to enhance experimentally induced cough in cats and guinea pigs following nasal antigen challenge in sensitised animals [137, 138].

\section{Angiotensin-converting enzyme inhibitors}

Chronic systemic treatment with several angiotensin-converting enzyme inhibitors potentiates the irritant-induced and spontaneous cough in guinea pigs [124, 144, 145].

\section{Cigarette smoke exposure}

Chronic mainstream or sidestream cigarette smoke exposure can lead to an enhanced cough response to tussive stimuli in a guinea pig model [146-148]. In some cases, this is associated with airway eosinophilia and neutrophilia [146]. In one study, environmental tobacco smoke increased citric-acid-induced cough and bronchoconstriction, and this was blocked, in part, by an $\mathrm{NK}_{1}$ receptor antagonist injected into the nucleus tractus solitarius [147].

The inflammatory processes present in some of these models have been suggested to alter the phenotype and/or the excitability of sensory airway afferents [149-151], which may lead to increased sensory input into the central control mechanisms that elicit cough. The mechanisms involved in this increased responsiveness have not yet been clearly defined, but the elucidation of specific pathways that sensitise this reflex may lead to the development of more effective therapeutics.

\section{Conclusion}

Cough, irrespective of which airways disease it is associated with, represents an unmet clinical need. There are no effective treatments available for cough, and those that are available have been shown to be ineffective [114]. It is, therefore, essential to identify and develop new treatments for cough. In order to achieve this end, it is necessary to develop and utilise an animal model of cough that accurately reflects the condition in humans. The guinea pig shows distinct advantages over other small rodents in that it coughs in response to given stimuli in the conscious state and that the physiology of the cough response reflects that in humans, and, for these reasons, 
the present task force recommends the use of this species as an investigational tool.

\section{Recommendations}

1) The most useful animal model of cough is the conscious guinea pig.

2) Both sound and airflow should be used to define a cough event.

\section{DESIGN AND CONDUCT OF CLINICAL TRIALS OF ANTITUSSIVE DRUGS}

Since acute cough is so common and chronic cough such a distressing and disabling symptom, it is unsurprising that novel antitussive treatments, both specific and nonspecific, are currently undergoing development. Cough in humans differs from that in animals, and compounds that may be highly effective in animal models, e.g. NK receptor antagonists, may fail in the clinic [152]. The demonstration of efficacy or lack of efficacy in humans is fraught with difficulties, including the choice of model, recruitment of subjects, choice of end-point, applicability to clinical research and overcoming the placebo effect. This section provides guidance in order to maximise the chance of providing a genuine result from any clinical pharmacology study.

\section{Choice of model}

Cough in clinical scenarios in which drug therapy is required differs from evoked cough in normal volunteers because the cough reflex is sensitised in disease. This is true of both acute [29] and chronic cough [22, 24], in which cough challenge dose-response curves are shifted to the left and return towards normal after either spontaneous resolution [29] or drug treatment [101, 153, 154]. The molecular cause of this cough reflex hypersensitivity is unknown. Airway inflammation leading to peripheral hypersensitivity of cough receptors would appear to be a reasonable explanation when the airways are inflamed, such as in acute viral bronchitis. A proliferation of nerves containing the putative cough receptor transient receptor potential vallinoid (TRPV) 1 has been demonstrated [155], although expression of this receptor may not be confined to the sensory neurons [156] Animal work supports the hypothesis that sensitisation occurs in the vagal ganglia located in the relay stations of the nodose and jugular parasympathetic ganglia [157]. Central modulation and hypersensitivity of the cough reflex certainly occurs [31]. Thus, in designing studies to test for antitussive activity, knowledge of the putative mode of action is vital. For example, leukotriene antagonists have been demonstrated to be effective in cough variant asthma [153], and are one of the mainstays of clinical treatment when inhaled steroids alone prove ineffective. When tested in cough challenge models in classic asthma, however, they are ineffective [158]. This is because the heightened cough reflex is due to the asthmatic inflammation, particularly the clustering of mast cells around airway nerves [159]. In the absence of inflammation, no beneficial effect is seen from these agents. In contrast, in the development of a TRPV1 capsaicin receptor antagonist, it would not be unreasonable to assume that an effective agent should block capsaicin cough challenge in normal volunteers.
Cough is a vital protective reflex. Conditions with a demonstrably reduced cough reflex, such as stroke and Parkinson's disease, are associated with an increased incidence of aspiration and pneumonia. Care is required, therefore, in the design of clinical studies looking at nonspecific cough suppression. Thus, although the suppression of cough due to viral bronchitis is unlikely to have adverse consequences, suppression of cough in studies in which the patient population has a chronic productive cough may lead to inspiration of secretions and clinical worsening. However, even in situations in which there is increased sputum production, cough reflex sensitivity may be exaggerated. Whether the suppression of this abnormal reflex sensitivity to normal levels results in an improvement or deterioration in clinical status remains to be determined from future studies.

\section{Normal volunteer studies}

Studies in normal volunteers are almost invariably performed using cough challenge methodologies. Two challenges are commonly used, citric acid and capsaicin [25]. The challenges do not measure the same reflex sensitivity since there is little correlation between the sensitivities of the two challenges in an individual [23]. There is little to choose between the two modalities of challenge, and both have been used to demonstrate antitussive effects. Lack of knowledge regarding how these responses are related to what occurs in the clinic is a major weakness of cough challenge in normal subjects.

Subject selection should include a screening visit during which challenge is performed. There is a strong argument for excluding subjects who show cough responses only at high challenge concentrations. In these subjects, it is difficult to demonstrate cough suppression because they are already approaching the maximum tolerable dose, and nonspecific effects, such as a burning sensation with capsaicin or a choking sensation with citric acid, mask any therapeutic effect [18].

\section{The placebo response}

In normal volunteer challenge studies, the placebo response is a major factor. A reduction in cough challenge of $>30 \%$ can be seen with placebo, and this effect may continue for several hours [160]. Indeed, the pharmacokinetics of placebo activity in cough challenge have been modelled [39]. A number of strategies have been used in an attempt to minimise this, e.g. performing a screening experiment with a placebo described as an antitussive and excluding responders, randomisation of challenge administration and using subjects previously known to exhibit a small response to placebo. None of these strategies appear to be effective. Studies should be designed with the probability that a considerable placebo response may occur whatever precautions are taken.

\section{Sex}

Females exhibit a heightened cough reflex $[49,51]$. On average, females cough twice as much as males to any given cough challenge, or, conversely, $\mathrm{C} 2$ and $\mathrm{C} 5$ are consistently lower in female subjects. The cause of this sex-related difference is unknown, but it also occurs in patients attending the cough clinic [22] and those receiving angiotensin-converting enzyme inhibitors [161]. Provided this fact is understood in the design of exclusion criteria, there is no reason for differential treatment of males and females within normal volunteer studies. 


\section{Normal volunteer studies with airway inflammation}

In an attempt to obtain a model that has some of the elements of clinically relevant cough in normal subjects, smokers with cough have been recruited to clinical studies [162]. These subjects provide another end-point, i.e. their smoker's cough, and also represent a state in which there is airway inflammation. In the conduct of such studies it should be remembered that there is a profound effect of cigarette smoking on the cough reflex [163]. Indeed, smoking reduces cough reflex sensitivity and approximately halves the number of coughing episodes per hour. Thus, the key time for observing drug effects is after overnight abstinence, with the subject refraining from smoking for the duration of the study.

Although giving a model of "natural" cough, the use of smokers may confound the study of certain groups of agents. In particular, the negative effect of smoking on inhaled steroid efficacy has been well described [164].

\section{Studies in patients}

Perhaps the major difficulty in the study of clinically important cough is defining the study population.

\section{Acute cough}

Acute cough is a benign self-limiting condition. Having recruited a study population, there is an inevitable marked spontaneous regression back to normality. This, coupled with a particularly powerful placebo effect $[165,166]$, makes the study of subjects with acute cough highly challenging. These factors, but particularly the daily variation in baseline, make crossover studies virtually impossible. Since there is individual variability in response, any parallel group study must be of a large size in order to convincingly show efficacy. Indeed, the only robust study demonstrating antitussive efficacy in acute cough is a meta-analysis of $>300$ subjects [167]. This study undertook laborious aural analysis of cough data. More recently, digital cough recorders offer the opportunity for objective cough frequency measurement, which may become the gold standard for such studies in future $[73,80,83,160]$. Until then, subjective cough scores, VASs and, again more recently, quality-of-life measurements may be used as end-points $[8,9]$.

\section{Post-viral cough}

Cough which persists after an arbitrarily defined 2-week period may be termed post-viral cough [6]. Again, spontaneous remission of symptoms is the rule, but this group of patients have been successfully used to demonstrate, for example, the effect of inhaled steroids on post-viral cough. Recruitment is obviously quite seasonal and can be very slow.

\section{Chronic cough}

Confusion exists in the categorisation of patients with chronic cough. This, in part, explains the wide variation in the proportion of patients diagnosed with the various cough syndromes in reports from cough clinics [168]. It is thus perhaps better to define the study population according to the presence or absence of a particular diagnostic result rather than use diagnostic labels about which there is disagreement. Patients with reflux disease may, through aspiration, show bronchial hyperresponsiveness [169]. Similarly, patients with asthma may also exhibit reflux symptoms [170]. In the study of asthmatic cough, it is better to define the study population on the basis of showing methacholine bronchial hyperresponsiveness or sputum eosinophilia. Similarly, patients with reflux disease should have a proven diagnosis from objective testing in the knowledge that many other patients will be excluded who also have reflux disease, but at least this is a certain entry criterion. A similar situation exists in studies of classic asthma where entry into a study is predicated by reversibility testing, even though only a small percentage of asthmatics fit into these reversibility criteria. One interesting group of patients for study are those who fail to meet the diagnostic criteria for a cough syndrome or fail multiple trials of appropriate therapy. They have been termed idiopathic cough patients and are frequently found in cough clinics. Unlike the situation in acute cough, these patients do not show placebo effects, and, since cough is reproducible, crossover studies are possible, limiting the number of subjects required [107].

\section{Recommendations}

1) The experimental model in which antitussive drugs are tested depends greatly upon the mode of action of the agent.

2) Normal volunteer studies should be designed in the knowledge that a large placebo effect is likely.

3) In acute cough, parallel group studies are required.

4) In chronic cough, the patient population studied should be defined by a diagnostic test.

\section{REFERENCES}

1 Office of Population Censuses and Surveys, Morbidity Statistics from General Practice: 4th National Study 19911992. Series MB5 no. 3. London, Her Majesty's Stationery Office, 1995.

2 Schappert SM. Ambulatory care visits of physician offices, hospital outpatient departments, and emergency departments: United States, 1995. Vital Health Stat 13 1997; 129: 1-38.

3 Fendrick AM, Monto AS, Nightengale B, Sarnes M. The economic burden of non-influenza-related viral respiratory tract infection in the United States. Arch Intern Med 2003; 163: 487-494.

4 Irwin RS, Curley FJ, French CL. Chronic cough. The spectrum and frequency of causes, key components of the diagnostic evaluation, and outcome of specific therapy. Am Rev Respir Dis 1990; 141: 640-647.

5 McGarvey LPA, Heaney LG, MacMahon J. A retrospective survey of diagnosis and management of patients presenting with chronic cough to a general chest clinic. Int J Clin Pract 1998; 52: 158-161.

6 Morice AH, Fontana GA, Sovijarvi ARA, et al. The diagnosis and management of chronic cough. Eur Respir J 2004; 24: 481-492.

7 Irwin RS, Baumann MH, Bolser DC, et al. Diagnosis and management of cough executive summary. ACCP evidence-based clinical practice guidelines. Chest 2006; 129: Suppl. 1, 1S-23S.

8 French CT, Irwin RS, Fletcher KE, Adams TM. Evaluation of cough-specific quality of life questionnaire. Chest 2002; 121: 1123-1131. 
9 Birring SS, Prudon B, Carr AJ, Singh SJ, Morgan MDL, Pavord ID. Development of a symptom specific health status measure for patients with chronic cough: Leicester Cough Questionnaire (LCQ). Thorax 2003; 58: 339-343. Online version: http://thorax.bmjjournals.com/cgi/ content/full/58/4/339. Date updated: April 2003. Date accessed: January 2007.

10 Laude EA, Higgins KS, Morice AH. A comparative study of the effects of citric acid, capsaicin and resiniferatoxin on the cough challenge in guinea-pig and man. Pulm Pharmacol 1993; 6: 171-175.

11 Dicpinigaitis PV. Short- and long-term reproducibility of capsaicin cough challenge testing. Pulm Pharmacol Ther 2003; 16: 61-65.

12 Widdicombe J, Fontana G. Cough: what's in a name? Eur Respir J 2006; 28: 10-15.

13 Korpas J, Tomori Z. Cough and Other Respiratory Reflexes. Basle, S. Karger, 1979.

14 Morice AH, McGarvey L, Pavord I. Recommendations for the management of cough in adults. Thorax 2006; 61: Suppl. 1, i1-i24.

15 Collier JG, Fuller RW. Capsaicin inhalation in man and the effects of sodium cromoglycate. Br J Pharmacol 1984; 81: 113-117.

16 Bickerman HA, Barach AL, Itkin S, Drimmer F. Experimental production of cough in human subjects induced by citric acid aerosols. Preliminary studies on the evaluation of antitussive agents. Am J Med Sci 1954; 228: 156-163.

17 Bickerman HA, German E, Cohen BM. The cough response of healthy human subjects stimulated by citric acid aerosol. Am J Med Sci 1957; 234: 191-205.

18 Midgren B, Hansson L, Karlsson JA, Simonsson BG, Persson CGA. Capsaicin-induced cough in humans. Am Rev Respir Dis 1992; 146: 347-351.

19 Fujimura M, Kamio Y, Hashimoto T, Matsuda T. Cough receptor sensitivity and bronchial responsiveness in patients with only chronic nonproductive cough: in view of effect of bronchodilator therapy. J Asthma 1994; 31: 463-472.

20 Dicpinigaitis PV, Dobkin JB. Antitussive effect of the GABA-agonist baclofen. Chest 1997; 111: 996-999.

21 Kopec SE, DeBellis RJ, Irwin RS. Chemical analysis of freshly prepared and stored capsaicin solutions: implications for tussigenic challenges. Pulm Pharmacol Ther 2002; 15: 529-534.

22 Kastelik JA, Thompson RH, Aziz I, Ojoo JC, Redington AE, Morice AH. Sex-related differences in cough reflex sensitivity in patients with chronic cough. Am J Respir Crit Care Med 2002; 166: 961-964.

23 Wong $\mathrm{CH}$, Matai R, Morice AH. Cough induced by low pH. Respir Med 1999; 93: 58-61.

24 Wong $\mathrm{CH}$, Morice AH. Cough threshold in patients with chronic obstructive pulmonary disease. Thorax 1999; 54: 62-64.

25 Morice AH, Kastelik JA, Thompson R. Cough challenge in the assessment of cough reflex. Br J Clin Pharmacol 2001; 52: 365-375.

26 Nejla S, Fujimura M, Kamio Y. Comparison between tidal breathing and dosimeter methods in assessing cough receptor sensitivity to capsaicin. Respirology 2000; 5: 337-342.

27 Barros MJ, Zammattio SL, Rees PJ. Effect of changes in inspiratory flow rate on cough responses to inhaled capsaicin. Clin Sci (Lond) 1991; 81: 539-542.

28 Barros MJ, Zammattio SJ, Rees PJ. Importance of inspiratory flow rate in the cough response to citric acid inhalation in normal subjects. Clin Sci (Lond) 1990; 78: 521-525.

29 O'Connell F, Thomas VE, Studham JM, Pride NB, Fuller RW. Capsaicin cough sensitivity increases during upper respiratory infection. Respir Med 1996; 90: 279-286.

30 Hansson L, Wollmer P, Dahlback M, Karlsson JA. Regional sensitivity of human airways to capsaicininduced cough. Am Rev Respir Dis 1992; 145: 1191-1195.

31 Hutchings HA, Morris S, Eccles R, Jawad MS. Voluntary suppression of cough induced by inhalation of capsaicin in healthy volunteers. Respir Med 1993; 87: 379-382.

32 Prudon B, Vara DD, Pavord ID, Birring SS. Analysis of cough reflex sensitivity data. Thorax 2005; 60: Suppl. II, ii107.

33 Prudon B, Birring SS, Vara DD, Hall AP, Thompson JP, Pavord ID. Cough and glottic-stop reflex sensitivity in health and disease. Chest 2005; 127: 550-557.

34 Crapo RO, Casaburi R, Coates AL, et al. Guidelines for methacholine and exercise challenge testing - 1999. Am J Respir Crit Care Med 2000; 161: 309-329.

35 Morice AH, Higgins KS, Yeo WW. Adaptation of cough reflex with different types of stimulation. Eur Respir J 1992; 5: 841-847.

36 Schmidt D, Jorres RA, Magnussen H. Citric acid-induced cough thresholds in normal subjects, patients with bronchial asthma, and smokers. Eur J Med Res 1997; 2: 384-388.

37 Barber CM, Curran AD, Bradshaw LM, Morice AH, Rawbone R, Fishwick D. Reproducibility and validity of a Yan-style portable citric acid cough challenge. Pulm Pharmacol Ther 2005; 18: 177-180.

38 Grattan TJ, Marshall AE, Higgins KS, Morice AH. The effect of inhaled and oral dextromethorphan on citric acid induced cough in man. Br J Clin Pharmacol 1995; 39: 261-263.

39 Morice AH, Marshall AE, Higgins KS, Grattan TJ. Effect of inhaled menthol on citric acid induced cough in normal subjects. Thorax 1994; 49: 1024-1026.

40 Rostami-Hodjegan A, Abdul-Manap R, Wright CE, Tucker GT, Morice AH. The placebo response to citric acid-induced cough: pharmacodynamics and gender differences. Pulm Pharmacol Ther 2001; 14: 315-319.

41 Wright CE, Campbell RJ, Morice AH. Citric acid inhalation cough challenge in chronic cough patients and controls using the KOKO Digidoser. Proc Am Thorac Soc 2006; 3: A372.

42 Fujimura M, Kamio Y, Sakamoto S, Bando T, Myou S, Matsuda T. Tachyphylaxis to capsaicin-induced cough and its reversal by indomethacin, in patients with the sinobronchial syndrome. Clin Auton Res 1992; 2: 397-401.

43 Fujimura M, Sakamoto S, Kamio Y, Matsuda T. Effects of methacholine induced bronchoconstriction and procaterol induced bronchodilation on cough receptor 
sensitivity to inhaled capsaicin and tartaric acid. Thorax 1992; 47: 441-445.

44 Nieto L, de Diego A, Perpina M, et al. Cough reflex testing with inhaled capsaicin in the study of chronic cough. Respir Med 2003; 97: 393-400.

45 Wright CE, Jackson J, Thompson RH, Morice AH. Validation of the citric acid cough challenge using the KOKO Digidoser system in healthy adult volunteers. Proc Am Thorac Soc 2007 (in press).

46 Dicpinigaitis PV, Alva RV. Safety of capsaicin cough challenge testing. Chest 2005; 128: 196-202.

47 O'Connell F, Thomas VE, Pride NB. Adaptation of cough reflex with different types of stimulation. Eur Respir J 1992; 5: 1296-1297.

48 Dicpinigaitis PV, Rauf K. The influence of gender on cough reflex sensitivity. Chest 1998; 113: 1319-1321.

49 Fujimura M, Kasahara K, Kamio Y, Naruse M, Hashimoto T, Matsuda T. Female gender as a determinant of cough threshold to inhaled capsaicin. Eur Respir J 1996; 9: 1624-1626.

50 Thompson R, Wright C, Morice AH. Female gender and enhanced citric acid induced cough response. Thorax 1999; 54: Suppl. 3, A75.

51 Fujimura M, Sakamoto S, Kamio Y, Matsuda T. Sex difference in the inhaled tartaric acid cough threshold in non-atopic healthy subjects. Thorax 1990; 45: 633-634.

52 International Society for the Study of Cough. Who are we? www.hull.ac.uk/ISSC/who_are_we.html. Date last updated: January 2007. Date last accessed: January 2007.

53 Mercer TT. Production of therapeutic aerosols; principles and techniques. Chest 1981; 80: Suppl. 6, 813-818.

54 Sterk PJ, Plomp A, van de Vate JF, Quanjer PH. Physical properties of aerosols produced by several jet- and ultrasonic nebulizers. Bull Eur Physiopathol Respir 1984; 20: $65-72$.

55 Eschenbacher WL, Boushey HA, Sheppard D. Alteration in osmolarity of inhaled aerosols cause bronchoconstriction and cough, but absence of a permeant anion causes cough alone. Am Rev Respir Dis 1984; 129: 211-215.

56 Lavorini F, Fontana GA, Pantaleo T, et al. Fog-induced respiratory responses are attenuated by nedocromil sodium in humans. Am J Respir Crit Care Med 2001; 163: 1117-1120.

57 Fontana GA, Pantaleo T, Lavorini F, Boddi V, Panuccio P. A noninvasive electromyographic study on threshold and intensity of cough in humans. Eur Respir J 1997; 10: 983-989.

58 Fontana GA, Pantaleo T, Lavorini F, Benvenuti F, Gangemi S. Defective motor control of coughing in Parkinson's disease. Am J Respir Crit Care Med 1998; 158: 458-464.

59 Higenbottam T, Jackson M, Woolman P, Lowry R, Wallwork J. The cough response to ultrasonically nebulized distilled water in heart-lung transplantation patients. Am Rev Respir Dis 1989; 140: 58-61.

60 Morice AH, Turley AJ, Linton K. Human ACE gene polymorphism and distilled water induced cough. Thorax 1997; 52: 111-113.

61 Lowry R, Higenbottam T, Johnson T, Godden D. Inhibition of artificially induced cough in man by bronchodilators. Br J Clin Pharmacol 1987; 24: 503-510.
62 Lowry R, Wood A, Johnson T, Higenbottam T. Antitussive properties of inhaled bronchodilators on induced cough. Chest 1988; 93: 1186-1189.

63 Ventresca PG, Nichol GM, Barnes PJ, Chung KF. Inhaled furosemide inhibits cough induced by low chloride content solutions but not by capsaicin. Am Rev Respir Dis 1990; 142: 143-146.

64 Fontana GA, Pantaleo T, Lavorini F, Mutolo D, Polli G, Pistolesi M. Coughing in laryngectomized patients. Am J Respir Crit Care Med 1999; 160: 1578-1584.

65 Tanaka S, Hirata K, Kurihara N, Yoshikawa J, Takeda T. Effect of loratadine, an $\mathrm{H}_{1}$ antihistamine, on induced cough in non-asthmatic patients with chronic cough. Thorax 1996; 51: 810-814.

66 Fontana GA, Pantaleo T, Lavorini F, Maluccio NM, Mutolo D, Pistolesi M. Repeatability of cough-related variables during fog challenges at threshold and suprathreshold stimulus intensity in humans. Eur Respir J 1999; 13: 1447-1450.

67 Woolf CR, Rosenberg A. Objective assessment of cough suppressants under clinical conditions using a tape recorder system. Thorax 1964; 19: 125-130.

68 Loudon RG, Brown LC. Cough frequency in patients with respiratory disease. Am Rev Respir Dis 1967; 96: 1137-1143.

69 Loudon RG, Spohn SK. Cough frequency and infectivity in patients with pulmonary tuberculosis. Am Rev Respir Dis 1969; 99: 109-111.

70 Archer LNJ, Simpson H. Night cough counts and diary card scores in asthma. Arch Dis Child 1985; 60: 473-474.

71 Hiew Y, Smith JA, Cheetham BMG, Earis JE, Woodcock AA. Automatic cough detection using digital signal processing techniques - the Manchester Cough Algorithm. Am J Respir Crit Care Med 2002; 165: A832.

72 Birring SS, Matos S, Patel RB, Evans DH, Pavord ID. The relationship between cough counts and quality of life in patients with chronic cough. Eur Respir J 2004; 24: Suppl. $48,47 \mathrm{~s}$.

73 Barry SJ, Dane AD, Morice AH, Walmsley AD. The automatic recognition and counting of cough. Cough 2006; 2: 8.

74 Bennett FM, Irwin RS, Brown L, French CL. Automatic recognition of coughs. Am Rev Respir Dis 1991; 143: A666.

75 Hsu JY, Stone RA, Logan-Sinclair RB, Worsdell M, Busst CM, Chung KF. Coughing frequency in patients with persistent cough: assessment using a 24 hour ambulatory recorder. Eur Respir J 1994; 7: 1246-1253.

76 Chang AB, Newman RG, Phelan PD, Robertson CF. A new use for an old Holter monitor: an ambulatory cough meter. Eur Respir J 1997; 10: 1637-1639.

77 Subburaj S, Hirtum AV, Quanten, S., Berckmans D. : An algorithm to automatically identify cough sounds from clinical recordings. Eur Respir J 2003; 22: Suppl. 45, 172s.

78 Smith JA, Cheetham BMG, Earis JE, Woodcock AA. Cough seconds: a new measure of cough. Am J Respir Crit Care Med 2006; 165: A832.

79 Coyle MA, Keenan BD, Mayleben DW, et al. Objective assessment of cough over a 24-hr period in patients with COPD. Am J Respir Crit Care Med 2004; 169: A606.

80 Smith J, Owen E, Earis J, Woodcock A. Effect of codeine on objective measurement of cough in chronic obstructive 
pulmonary disease. I Allergy Clin Immunol 2006; 117: 831-835.

81 Smith JA, Owen EC, Jones AM, Dodd ME, Webb AK, Woodcock A. Objective measurement of cough during pulmonary exacerbations in adults with cystic fibrosis. Thorax 2006; 61: 425-429.

82 Birring SS, Matos S, Patel RB, Prudon B, Evans DH, Pavord ID. Cough frequency, cough sensitivity and health status in patients with chronic cough. Respir Med 2006; 100: 1105-1109.

83 Matos S, Birring SS, Pavord ID, Evans DH. Detection of cough signals in continuous audio recordings using hidden Markov models. IEEE Trans Biomed Eng 2006; 53: 1078-1083.

84 Korpas J, Sadlonova J, Salat D, Masarova E. The origin of cough sounds. Bull Eur Physiopathol Respir 1987; 23: Suppl. 10, 47s-50s.

85 Hamutcu R, Francis J, Karakoc F, Bush A. Objective monitoring of cough in children with cystic fibrosis. Pediatr Pulmonol 2002; 34: 331-335.

86 Thorpe CW, Toop LJ, Dawson KP. Towards a quantitative description of asthmatic cough sounds. Eur Respir J 1992; 5: 685-692.

87 Olia PM, Sestini P, Vagliasindi M. Acoustic parameters of voluntary cough in healthy non-smoking subjects. Respirology 2000; 5: 271-275.

88 Corrigan DL, Paton JY. Pilot study of objective cough monitoring in infants. Pediatr Pulmonol 2003; 35: 350-357.

89 Smith JA, Earis A, Woodcock AA, Earis JE. Acoustic properties of spontaneous coughs in common respiratory diseases. Am J Respir Crit Care Med 2004; 169: A200.

90 Bland JM, Altman DG. Comparing methods of measurement: why plotting difference against standard method is misleading. Lancet 1995; 346: 1085-1087.

91 World Health Organization. Preamble to the Constitution of the World Health Organization as adopted by the International Health Conference, New York, 19 June - 22 July 1946; signed on 22 July 1946 by the representatives of 61 States (Official Records of the World Health Organization, no. 2, p. 100) and entered into force on 7 April 1948.

92 French CL, Irwin RS, Curley FJ, Krikorian CJ. Impact of chronic cough on quality of life. Arch Intern Med 1998; 158: 1657-1661.

93 Gulsvik A, Refvem OK. A scoring system on respiratory symptoms. Eur Respir J 1988; 1: 428-432.

94 Chang $A B$, Newman RG, Carlin JB, Phelan PD, Robertson CF. Subjective scoring of cough in children: parent-completed vs child-completed diary cards vs an objective method. Eur Respir J 1998; 11: 462-466.

95 Ellul-Micallef R. Effect of terbutaline sulphate in chronic "allergic" cough. Br Med J (Clin Res Ed) 1983; 287: 940-943.

96 Faniran AO, Peat JK, Woolcock AJ. Measuring persistent cough in children in epidemiological studies: development of a questionnaire and assessment of prevalence in two countries. Chest 1999; 115: 434-439.

97 Brunekreef B, Groot B, Rijcken B, Hoek G, Steenbekkers A, de Boer A. Reproducibility of childhood respiratory symptom questions. Eur Respir J 1992; 5: 930-935.
98 Birring SS, Brightling CE, Symon FA, Wardlaw AJ Pavord ID. Idiopathic chronic cough: association with organ specific autoimmune disease and bronchoalveolar lymphocytosis. Thorax 2003; 58: 1066-1070.

99 Brightling CE, Monterio W, Green RH, et al. Induced sputum and other outcome measures in chronic obstructive pulmonary disease: safety and repeatability. Respir Med 2001; 95: 999-1002.

100 Birring SS, Passant C, Patel RB, Prudon B, Murty GE, Pavord ID. Chronic tonsillar enlargement and cough: preliminary evidence of a novel and treatable cause of chronic cough. Eur Respir J 2004; 23: 199-201.

101 Brightling CE, Ward R, Wardlaw AJ, Pavord ID. Airway inflammation, airway responsiveness and cough before and after inhaled budesonide in patients with eosinophilic bronchitis. Eur Respir J 2000; 15: 682-686.

102 Fayers PM, Machin D. Quality of Life: Assessment, Analysis and Interpretation. 1st Edn. Chichester, John Wiley \& Sons, 2000.

103 Juniper EF. Health-related quality of life. In: Barnes PJ., Grunstein MM., Leff AR., Woodcock AJ, eds. Asthma. Philadelphia, Lippincott-Raven, 1997; pp. 1487-1497.

104 Baiardini I, Braido F, Fassio O, et al. A new tool to assess and monitor the burden of chronic cough on quality of life: Chronic Cough Impact Questionnaire. Allergy 2005; 60: 482-488.

105 Birring SS, Patel RB, Carr AJ, Singh SJ, Morgan MDL, Pavord ID. Assessment of quality of life in acute cough with the Leicester Cough Questionnaire (LCQ). Am J Respir Crit Care Med 2004; 169: A509.

106 Raj AA, Pavord ID, Birring SS. What is the minimal important difference of the Leicester Cough Questionnaire? Thorax 2006; 21: Suppl. 2, 109.

107 Morice AH, Menon MS, Mulrennan SA, et al. Opiate therapy in chronic cough. Am J Respir Crit Care Med 2007; 175: 312-315.

108 French CT, Fletcher KE, Irwin RS. A comparison of gender differences in health-related quality of life in acute and chronic coughers. Chest 2005; 127: 1991-1998.

109 French CT, Fletcher KE, Irwin RS. Gender differences in health-related quality of life in patients complaining of chronic cough. Chest 2004; 125: 482-488.

110 Birring SS, Patel RB, Prudon B, Singh SJ, Morgan MDL, Pavord ID. Quality of life in chronic cough. Am J Respir Crit Care Med 2003; 167: A135.

111 Dicpinigaitis PV, Tso R, Banauch GI. Prevalence of depressive symptoms among patients with chronic cough. Chest 2006; 130: 1839-1843.

112 Kalpaklioglu AF, Kara T, Kurtipek E, Kocyigit P, Ekici A, Ekici M. Evaluation and impact of chronic cough: comparison of specific vs generic quality-of-life questionnaires. Ann Allergy Asthma Immunol 2005; 94: 581-585.

113 Choudry NB, Fuller RW. Sensitivity of the cough reflex in patients with chronic cough. Eur Respir J 1992; 5: 296-300.

114 Schroeder K, Fahey T. Systematic review of randomised controlled trials of over the counter cough medicines for acute cough in adults. BMJ 2002; 324: 1-6.

115 Karlsson JA, Fuller RW. Pharmacological regulation of the cough reflex - from experimental models to antitussive effects in man. Pulm Pharmacol Ther 1999; 12: 215-228. 
116 Moreaux B, Beerens D, Gustin P. Development of a cough induction test in pigs: effects of SR 48968 and enalapril. J Vet Pharmacol Ther 1999; 22: 387-389.

117 Kamei J, Hukuhara T, Kasuya Y. Dopaminergic control of the cough reflex as demonstrated by the effects of apomorphine. Eur J Pharmacol 1987; 141: 511-513.

118 Korpas J. Differentiation of the expiration and the cough reflex. Physiol Bohemoslov 1972; 21: 677-680.

119 Karlsson JA, Sant'Ambrogio G, Widdicombe J. Afferent neural pathways in cough and reflex bronchoconstriction. J Appl Physiol 1988; 65: 1007-1023.

120 Forsberg K, Karlsson JA, Theodorsson E, Lundberg JM, Persson CG. Cough and bronchoconstriction mediated by capsaicin-sensitive sensory neurons in the guinea-pig. Pulm Pharmacol 1988; 1: 33-39.

121 Fox AJ, Barnes PJ, Urban L, Dray A. An in vitro study of the properties of single vagal afferents innervating guinea-pig airways. J Physiol 1993; 469: 21-35.

122 Undem BJ, Carr MJ, Kollarik M. Physiology and plasticity of putative cough fibres in the Guinea pig. Pulm Pharmacol Ther 2002; 15: 193-198.

123 Fox AJ. Modulation of cough and airway sensory fibres. Pulm Pharmacol 1996; 9: 335-342.

124 Fox AJ, Lalloo UG, Belvisi MG, Bernareggi M, Chung KF, Barnes PJ. Bradykinin-evoked sensitization of airway sensory nerves: a mechanism for ACE-inhibitor cough. Nat Med 1996; 2: 814-817.

125 Fox AJ, Barnes PJ, Venkatesan P, Belvisi MG. Activation of large conductance potassium channels inhibits the afferent and efferent function of airway sensory nerves in the guinea pig. J Clin Invest 1997; 99: 513-519.

126 Tatar M, Pecova R, Karcolova D. Sensitivity of the cough reflex in awake guinea pigs, rats and rabbits. Bratisl Lek Listy 1997; 98: 539-543.

127 Lalloo UG, Fox AJ, Belvisi MG, Chung KF, Barnes PJ. Capsazepine inhibits cough induced by capsaicin and citric acid but not by hypertonic saline in guinea pigs. $J$ Appl Physiol 1995; 79: 1082-1087.

128 Hay DW, Giardina GA, Griswold DE, et al. Nonpeptide tachykinin receptor antagonists. III. SB 235375, a low central nervous system-penetrant, potent and selective neurokinin-3 receptor antagonist, inhibits citric acidinduced cough and airways hyper-reactivity in guinea pigs. J Pharmacol Exp Ther 2002; 300: 314-323.

129 Emonds-Alt X, Advenier C, Cognon C, et al. Biochemical and pharmacological activities of SR 144190, a new potent non-peptide tachykinin $\mathrm{NK}_{2}$ receptor antagonist. Neuropeptides 1997; 31: 449-458.

130 Belvisi MG, Venkatesan P, Barnes PJ, Fox AJ. A comparison of the chemosensitivity of the isolated guinea pig and human vagus nerves. Am J Respir Crit Care Med 1998; 157: A487.

131 Canning BJ, Mazzone SB, Meeker SN, Mori N, Reynolds SM, Undem BJ. Identification of the tracheal and laryngeal afferent neurones mediating cough in anaesthetized guinea-pigs. J Physiol 2004; 557: 543-558.

132 Mazzone SB, Mori N, Canning BJ. Synergistic interactions between airway afferent nerve subtypes regulating the cough reflex in guinea-pigs. J Physiol 2005; 569: 559-573.
133 Bolser DC, Hey JA, Chapman RW. Influence of central antitussive drugs on the cough motor pattern. J Appl Physiol 1999; 86: 1017-1024.

134 Bolser DC, Mcleod RL, Tulshian DB, Hey JA. Antitussive action of nociceptin in the cat. Eur J Pharmacol 2001; 430: 107-111.

135 Bolser DC, Aziz SM, DeGennaro FC, et al. Antitussive effects of GABAB agonists in the cat and guinea-pig. $\mathrm{Br} J$ Pharmacol 1993; 110: 491-495.

136 Tatar M, Pecova R. Laryngeal and tracheobronchial cough in anaesthetized cats and guinea-pigs. Stud Pneumol Phtiseol 1994; 54: 143-145.

137 Plevkova J, Kollarik M, Brozmanova M, Revallo M, Varechova S, Tatar M. Modulation of experimentallyinduced cough by stimulation of nasal mucosa in cats and guinea pigs. Respir Physiol Neurobiol 2004; 142: 225-235.

138 Tatar M, Karcolova D, Pecova R, Kollarik M, Plevkova J, Brozmanova M. Experimental modulation of the cough reflex. Eur Respir Rev 2002; 12: 264-269.

139 Widdicombe J. Sensory mechanisms. Pulm Pharmacol 1996; 9: 383-387.

140 Moreaux B, Nemmar A, Beerens D, Gustin P. Inhibiting effect of ammonia on citric acid-induced cough in pigs: a possible involvement of substance P. Pharmacol Toxicol 2000; 87: 279-285.

141 Xiang A, Uchida Y, Nomura A, et al. Effects of airway inflammation on cough response in the guinea pig. J Appl Physiol 1998; 85: 1847-1854.

142 Liu Q, Fujimura M, Tachibana H, Myou S, Kasahara K, Yasui M. Characterization of increased cough sensitivity after antigen challenge in guinea pigs. Clin Exp Allergy 2001; 31: 474-484.

143 House A, Celly C, Skeans S, et al. Cough reflex in allergic dogs. Eur J Pharmacol 2004; 492: 251-258.

144 Hirata R, Nabe T, Kohno S. Augmentation of spontaneous cough by enalapril through up-regulation of bradykinin B1 receptors in guinea pigs. Eur J Pharmacol 2003; 474: 255-260.

145 Ito K, Ito K, Sawada Y, Kamei J, Misawa M, Iga T. Toxicodynamic analysis of cough and inflammatory reactions by angiotensin-converting enzyme inhibitors in guinea pig. J Pharmacol Exp Ther 1995; 275: 920-925.

146 Bergren DR. Chronic tobacco smoke exposure increases cough to capsaicin in awake guinea pigs. Respir Physiol 2001; 126: 127-140.

147 Joad JP, Munch PA, Bric JM, et al. Passive smoke effects on cough and airways in young guinea pigs: role of brainstem substance P. Am J Respir Crit Care Med 2004; 169: 499-504.

148 Karlsson JA, Zackrisson C, Lundberg JM. Hyperresponsiveness to tussive stimuli in cigarette smoke-exposed guinea-pigs: a role for capsaicin-sensitive, calcitonin gene-related peptide-containing nerves. Acta Physiol Scand 1991; 141: 445-454.

149 Myers AC, Kajekar R, Undem BJ. Allergic inflammationinduced neuropeptide production in rapidly adapting afferent nerves in guinea pig airways. Am J Physiol Lung Cell Mol Physiol 2002; 282: L775-L781.

150 Hunter DD, Myers AC, Undem BJ. Nerve growth factorinduced phenotypic switch in guinea pig airway sensory neurons. Am J Respir Crit Care Med 2000; 161: 1985-1990. 
151 Riccio MM, Myers AC, Undem BJ. Immunomodulation of afferent neurons in guinea-pig isolated airway. J Physiol 1996; 491: 499-509.

152 Advenier $\mathrm{C}$. Tachykinin $\mathrm{NK}_{2}$ receptors further characterized in the lung with nonpeptide receptor antagonists. Can J Physiol Pharmacol 1995; 73: 878-884.

153 Dicpinigaitis PV, Dobkin JB, Reichel J. Antitussive effect of the leukotriene receptor antagonist zafirlukast in subjects with cough-variant asthma. J Asthma 2002; 39: 291-297.

154 O'Connell F, Thomas VE, Pride NB, Fuller RW. Capsaicin cough sensitivity decreases with successful treatment of chronic cough. Am J Respir Crit Care Med 1994; 150: 374-380.

155 Groneberg DA, Niimi A, Dinh QT, et al. Increased expression of transient receptor potential vanilloid-1 in airway nerves of chronic cough. Am J Respir Crit Care Med 2004; 170: 1276-1280.

156 Mitchell JE, Campbell AP, New NE, et al. Expression and characterization of the intracellular vanilloid receptor (TRPV1) in bronchi from patients with chronic cough. Exp Lung Res 2005; 31: 295-306.

157 Undem BJ, Chuaychoo B, Lee MG, Weinreich D, Myers AC, Kollarik M. Subtypes of vagal afferent Cfibres in guinea-pig lungs. J Physiol 2004; 556: 905-917.

158 Dicpinigaitis PV, Dobkin JB. Effect of zafirlukast on cough reflex sensitivity in asthmatics. J Asthma 1999; 36: 265-270.

159 Brightling CE, Bradding P, Symon FA, Holgate ST, Wardlaw AJ, Pavord ID. Mast cell infiltration of airway smooth muscle in asthma. N Engl J Med 2002; 346: 1699-1705.

160 Manap RA, Wright CE, Gregory A, et al. The antitussive effect of dextromethorphan in relation to CYP2D6 activity. Br J Clin Pharmacol 1999; 48: 382-387.
161 Coulter DM, Edwards IR. Cough associated with captopril and enalapril. Br Med J (Clin Res Ed) 1987; 294: 1521-1523.

162 Mulrennan S, Wright C, Thompson R, Goustas P, Morice A. Effect of salbutamol on smoking related cough. Pulm Pharmacol Ther 2004; 17: 127-131.

163 Dicpinigaitis PV. Cough reflex sensitivity in cigarette smokers. Chest 2003; 123: 685-688.

164 Tomlinson JE, McMahon AD, Chaudhuri R, Thompson JM, Wood SF, Thomson NC. Efficacy of low and high dose inhaled corticosteroid in smokers versus non-smokers with mild asthma. Thorax 2005; 60: 282-287.

165 Eccles R, Morris S, Jawad M. Lack of effect of codeine in the treatment of cough associated with acute upper respiratory tract infection. J Clin Pharm Ther 1992; 17: 175-180.

166 Eccles R. The powerful placebo in cough studies? Pulm Pharmacol Ther 2002; 15: 303-308.

167 Pavesi L, Subburaj S, Porter-Shaw K. Application and validation of a computerized cough acquisition system for objective monitoring of acute cough: a meta-analysis. Chest 2002; 120: 1121-1128.

168 Morice AH, Kastelik JA. Cough. 1: Chronic cough in adults. Thorax 2003; 58: 901-907.

169 Kiljander TO, Salomaa ER, Hietanen EK, Ovaska J, Helenius H, Liippo K. Gastroesophageal reflux and bronchial responsiveness: correlation and the effect of fundoplication. Respiration 2002; 69: 434-439.

170 Harding SM. Recent clinical investigations examining the association of asthma and gastroesophageal reflux. Am J Med 2003; 115: Suppl. 3A, 39S-44S. 